\title{
Study on the Relationship between Root Metal Flow Behavior and Root Flaw Formation of a 2024 Aluminum Alloy Joint in Friction Stir Welding by a Multiphysics Field Model
}

\author{
Jian Luo ${ }^{1,2,3, *}$, Jiafa Wang ${ }^{2}$, Hongxin Lin ${ }^{2}$, Lei Yuan ${ }^{4}$, Jianjun Gao ${ }^{2}$ and Haibin Geng $2,3(1)$ \\ 1 State Key Laboratory of Advanced Welding and Joining, Harbin Institute of Technology, \\ Harbin 150001, China \\ 2 College of Mechanical Engineering and Automation, Fuzhou University, Fuzhou 350116, China; \\ wjf13174517152@163.com (J.W.); linhongxin_edu@163.com (H.L.); \\ gjj410zd@fzu.edu.cn (J.G.); genghb@fzu.edu.cn (H.G.) \\ 3 State Key Laboratory of Solidification Processing, Northwestern Polytechnical University, \\ Xi'an 710072, China \\ 4 Beijing Special Vehicle Research Institute, Beijing 100072, China; yuanlei110119@126.com \\ * Correspondence: luojian@fzu.edu.cn; Tel.: +86-591-22866262
}

Received: 29 May 2020; Accepted: 2 July 2020; Published: 8 July 2020

\begin{abstract}
In friction stir welding (FSW), many defects (such as kissing bond, incomplete penetration, and weak connection) easily occur at the root of the welded joint. Based on the Levy-Mises yield criterion of the Zener-Hollomon thermoplastic constitutive equation, a 3D thermal-mechanical coupled finite element model was established. The material flow behavior and the stress field at the root area of a $6 \mathrm{~mm}$ thick 2024-T3 aluminum alloy FSW joint were studied. The influence of pin length on the root flaw was investigated, and the formation mechanism of the "S line" defects and non-penetration defects were revealed. The research results showed that the "S line" defect forms near the bottom surface of the pin owing to the insufficiently mixed material from the advancing side (AS) and retreating side (RS) near the weld center. The non-penetration defect forms near the bottom surface of the workpiece owing to the insufficient driving force to make the material flow through the weld center. With the continual increase of pin length, the size of the "S line" defect and non-penetration defect reduces, and finally, the defect-free welded joint can be obtained with an optimized suitable length of the pin in this case.
\end{abstract}

Keywords: friction stir welding; welding seam root; metal flow behavior; root flaw; pin length; Incomplete penetration; weak connection

\section{Introduction}

Friction stir welding (FSW) is a novel solid phase bonding technique developed by The Welding Institute (TWI) in 1991 [1]. During welding, heat input generated by the friction heat between the tool and the workpiece, and the plastic deformation of the welded metal changes the welded metal into a thermoplastic state. The plastic metal generates plastic flow and forms a closed joint under the combined action of the pin and the shoulder [2]. FSW is of high quality with a low welding heat input, no filler metal, no smoke, and no weld splash during the welding process, and it is of a green, environmentally friendly nature. FSW technology is often used for welding magnesium alloy, aluminum alloy, and other light alloy materials [3-5]. More importantly, in recent years, FSW technology shows great advantage in joining dissimilar alloys such as $\mathrm{Al}-\mathrm{Mg}-\mathrm{Si} / \mathrm{Al}-\mathrm{Zn}-\mathrm{Mg}$ alloy [6], Al/NiTi alloy [7], 
and $\mathrm{Al} /$ Steel [8]. However, FSW involves the changes of temperature, adhesive shear force, and metal flow behavior, which is a complex thermal-fluid coupled process. The root of the welded joint often forms a weak connection or kissing bond of " $\mathrm{S}$ " line and non-penetration defects due to insufficient fluidity of plastic materials and heat input.

The weak-connection defect at the root of the weld has a great influence on the mechanical properties of the FSW welded joint. Weak connection defects will reduce the plasticity of the joint. When there is a weak connection defect at the root of the weld, the fracture mode in the tensile test will be brittle. For well-formed welded joints, the fracture mode is plastic [9-11]. Jolu [12-14] investigated the effect of root flow on the tensile and fatigue behavior. They found that the root flaw acts as a crack initiation site during the tensile test, which reduces the yield strength of the welded joint by $40 \%$ and the ultimate tensile strength by $20 \%$. In the fatigue life test, they found that the tilting angle of the weak connection can influence the fatigue life of the welded joint. When the weak-connection defect is strongly tilted with respect to the loading direction, the fatigue life of the joint is higher. Zhou [15] studied the effect of weak connection defects on the fatigue strength of the FSW joint. They found that when the strain rate is $0.1 / \mathrm{s}$, the fatigue life of intact weld seams is 21 to 43 times longer than that of the weld seams with weak connection defects at the root, which is owing to the fact that fatigue cracks can generate from the weak connection line, resulting in a great reduction of the fatigue life of the weld. Kadlec [16] found that the size of the root flaw significantly affects the fatigue life of the welded joint. When the size of root flaw is $315 \mathrm{um}$, it does not affect the fatigue strength of the connection. However, the $670 \mathrm{um}$ size weak connection defect reduces the fatigue life of the joint to $91 \%$ of the base metal.

Due to the influence of root defects on the mechanical properties of FSW joints, many scholars began to pay attention to the formation mechanism of root defects and the relationship between the root defects and process parameters. Sato [10,17] and Okamura [18] studied the weak connection of the FSW welded joint of aluminum alloy. They found that "S line" defects originated from oxide film on the butt surface of the workpiece. During the FSW process, broken oxide particles form a black flow trace originated from the retreating side and extending to the advancing side. "S" shape weak connection lines distribute continuously in the welding direction, forming a weak bonding surface. Chen [19] used the numerical simulation method to quantitatively research the bonding behavior of the FSW joint. The numerical simulation results show that the weak connection defect is caused by the insufficient fluidity of the plastic material and heat input at the root of the welding seam, which leads to insufficient bonding pressure at the butt surface of the weld. Luo [20] studied material flow in the FSW process based on a computational fluid dynamic model; they found that the ratio of rotation speed to welding speed has an effect on the material flow behavior around the stirring pin, which is related to the defect formation in the FSW welded joint. Moussawi [21] studied the friction stir welding of DH36 and EH46 steels at different welding speeds and rotation speeds. They found that the high-speed movement of the stirring pin will result in insufficient fluidity of the weld material and weak connection defect at the root of the welded joint. Hou [22] and Zhou [23] found that the root flaws occur under high welding speed and low rotation speed owing to the insufficient heat input and material flow.

To eliminate the root flaw of the FSW welded joints, some scholars adopted the improved FSW method such as electricity-assisted friction stir welding (EAFSW) [24-26], bobbin tool friction stir welding (BTFSW) [27-29], and ultrasonic-assisted friction stir welding (UAFSW) [30,31], although the complex design of the stirring tool or the additional equipment induced by these methods increases the cost of the FSW process. In traditional FSW, some scholars believe that the root defects are caused by the improper selection of the pin length. Since the length of the pin has an important influence on the welding heat input, it also determines the forging behavior and extrusion pressure of the tool on the plastic material in the welding process [32]. However, if the pin is too long, its length will exceed the thickness of the base metal, which makes the backing plate adhere to the base material. If the pin is too short, a non-penetration defect will appear at the bottom surface of the workpiece [33]. Mandache [34] investigated the effect of pin length on the formation of defects at the root of the welding 
seam. They found that with the increase of the pin length, the size of the non-penetration defect decreases gradually, but the size of the defect of the weak connection fluctuates in a wavy manner.

Weak connection and non-penetration defects at the root of the weld have seriously affected the quality of the weld, but the existing studies have not revealed the formation mechanism of defects at the root of the weld from the flow mechanism, and there is no in-depth study on the mechanism of eliminating defects at the root with the length of tool pin. In this paper, the metal flow behavior at the root of the weld and the formation mechanism of weak connection defects were studied by the numerical simulation method, the influence of different tool pin lengths on the plastic metal flow behavior at the root of the weld was investigated, and the optimized suitable length of the pin with a non-defects welded joint was identified.

\section{Models}

\subsection{Geometry and Material Model}

A 2024-T3 aluminum alloy plate with a length of $120 \mathrm{~mm}$, a width of $35 \mathrm{~mm}$, and a thickness of $6 \mathrm{~mm}$ was used for the geometry model. The shoulder diameter of the stirring tool is $16 \mathrm{~mm}$ with concentric ring grooves. The diameter of the top and root of the pin is $6 \mathrm{~mm}$ and $3 \mathrm{~mm}$, respectively. The length of the pin is $\mathrm{L}$, which changes from 5.8 to $6.0 \mathrm{~mm}$. The conical angle $\theta$ changes from $14.5^{\circ}$ to $14^{\circ}$ with the pin length changing from 5.8 to $6.0 \mathrm{~mm}$. Figure 1 shows the diagram of the workpiece and the stirring tool with the corresponding size.
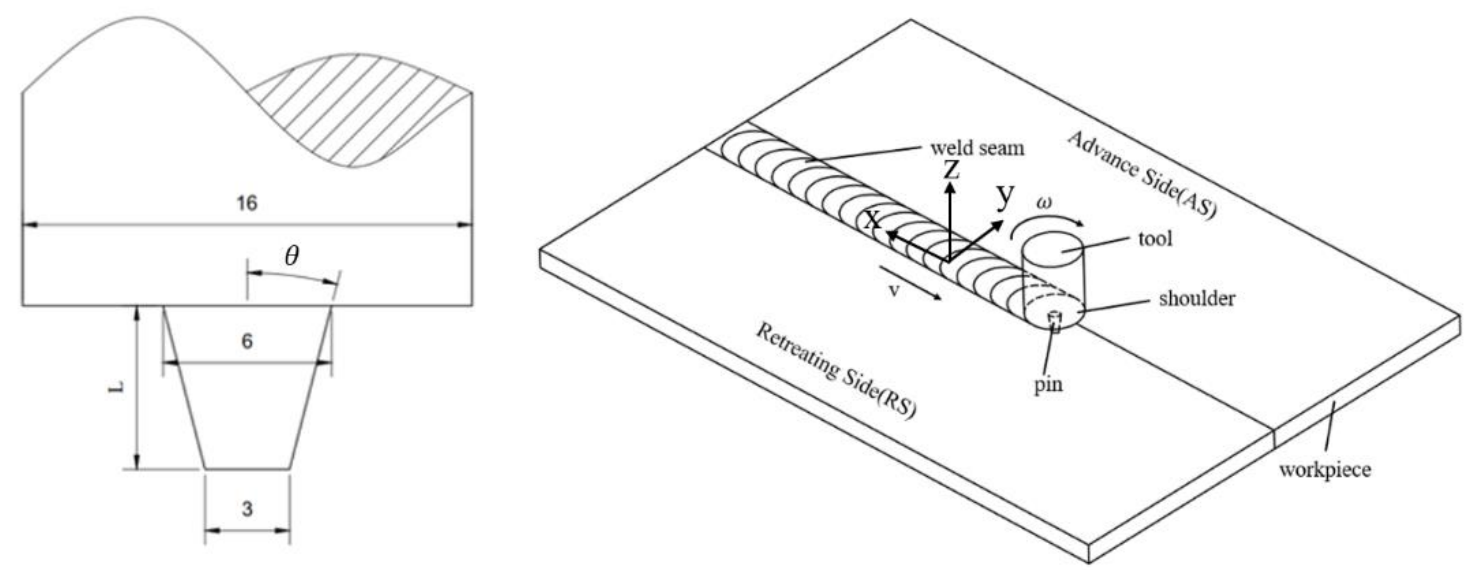

Figure 1. Schematic diagram of tool size and welding sample.

The chemical composition of 2024-T3 aluminum alloy is shown in Table 1. The thermal conductivity, specific heat capacity, thermal expansion coefficient, elastic modulus, Poisson's ratio, and other physical parameters of aluminum alloy 2024 are shown in Figure 2.

Table 1. Chemical composition of aluminum alloy 2024.

\begin{tabular}{cccccccccc}
\hline Chemical Component & $\mathbf{S i}$ & $\mathbf{F e}$ & $\mathbf{C u}$ & $\mathbf{M n}$ & $\mathbf{M g}$ & $\mathbf{N i}$ & $\mathbf{Z n}$ & $\mathrm{Ti}$ & $\mathrm{Al}$ \\
\hline Content $/ \mathrm{wt} \%$ & 0.5 & 0.5 & 3.8 & 0.3 & 1.3 & 0.1 & 0.3 & 0.09 & $\mathrm{Bal}$ \\
\hline
\end{tabular}




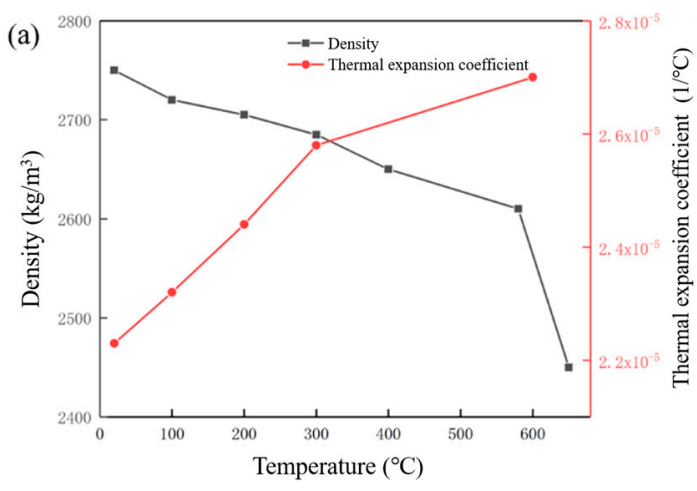

(a)

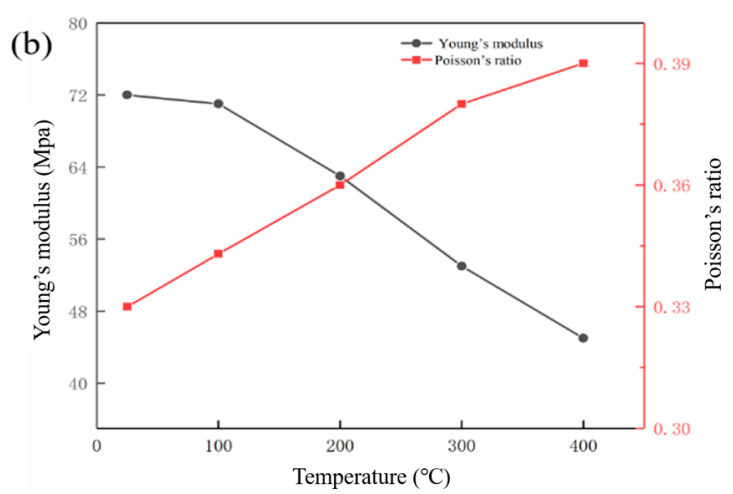

(b)

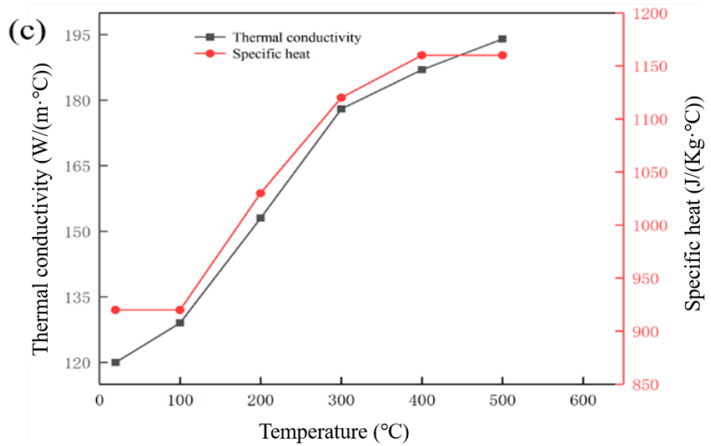

(c)

Figure 2. Thermophysical properties of aluminum alloy 2024 with temperature change. (a) Density and thermal expansion coefficient; (b) Young's modulus and Poisson's ratio; (c) thermal conduction coefficient and specific heat capacity [35].

\subsection{Heat Generation Model}

In the process of FSW, welding heat input includes three parts: (1) friction between the shoulder and the workpiece; (2) friction between the pin and the workpiece; and (3) plastic deformation of the material. According to the minimum torque required by the tool to overcome the rotation of friction, the heat produced by friction on the shoulder, the heat produced by friction on the side of the pin, and the heat produced by friction on the bottom of the pin can be calculated as:

$$
\begin{gathered}
Q_{\text {shoulder }}=\frac{4}{3} \pi^{2} \mu P N\left(R_{s}{ }^{3}-R_{2}{ }^{3}\right) \\
Q_{\text {pin-side }}=\frac{4 \pi^{2} N \mu P}{3 \sin \alpha}\left(R_{2}^{3}-R_{3}^{3}\right) \\
Q_{\text {pin-bottom }}=\frac{4}{3} \pi^{2} \mu P N R_{3}^{3}
\end{gathered}
$$

where $Q_{\text {shoulder }}, Q_{\text {pin-side, }}, Q_{\text {pin-bottom }}$ represent heat generation at the shoulder, heat generation at the side of the pin, and heat generation at the bottom of the pin, respectively. $\mu$ is the friction coefficient, $P$ is the welding pressure, $N$ is the rotating speed, $R_{S}$ is the shoulder radius, $R_{2}$ is the root radius of the pin, $R_{3}$ is the end radius of the pin, and $\alpha$ is the cone angle of the pin.

In the process of FSW, the material is subjected to severe plastic deformation. Most of the deformation work of the material is transferred to the surrounding area in the form of heat energy. This part of the deformation work accounts for about $90 \%$ of the deformation work, while the rest 
of the work is used in the plastic deformation of the material. The heat source density generated by plastic deformation is:

$$
q_{p}=\bar{\sigma} \alpha_{p} \dot{\bar{\varepsilon}}
$$

where $\mathrm{q}_{\mathrm{p}}$ is the heat source density of the plastic deformation of the material, $\bar{\sigma}$ is the equivalent stress, $\alpha_{\mathrm{p}}$ is the heat conversion efficiency, which is set as 0.9 , and $\dot{\bar{\varepsilon}}$ is the equivalent strain rate.

Therefore, the heat produced by plastic deformation of metal materials is:

$$
Q_{v}=\int_{v} \bar{\sigma} \alpha_{p} \dot{\bar{\varepsilon}} d V
$$

where $Q_{v}$ represents the plastic deformation heat production of the material with volume $V$.

\subsection{Material Flow Model}

A welding material is defined as a viscoplastic material. The mechanical response of viscoplastic materials can be defined by the constitutive relationship, hardening law, yield criterion, and flow rule. This paper has some reasonable assumptions without affecting the research results. First, the welding stage studied is a steady state-that is, the heat production and material flow reach a stable state. Second, the plastic softening material is a non-Newtonian, incompressible viscoplastic fluid. Third, elastic strains are negligible.

\subsubsection{Flow Rule}

The flow rule defines the change rate of various strain rate components during plastic deformation of the material, which is expressed in Equation (6):

$$
\varepsilon_{i j}^{p}=\lambda \frac{\partial g}{\partial \sigma_{i j}}
$$

where $\mathrm{g}$ is a scalar function of the invariants of the deviating stress and is called plastic potential, and $\lambda$ is a positive proportionality constant. When $g$ is equal to the yield function $f\left(\sigma_{i j}\right)$, Equation (6) is the associated flow rule and can be rewritten as Equation (7) [24]:

$$
\frac{\dot{\varepsilon}_{x}^{p}}{\sigma_{x}^{\prime}}=\frac{\dot{\varepsilon}_{y}^{p}}{\sigma_{y}^{\prime}}=\frac{\dot{\varepsilon}_{z}^{p}}{\sigma_{z}^{\prime}}=\frac{\dot{\gamma}_{x y}^{p}}{2 \tau_{x y}}=\frac{\dot{\gamma}_{y z}^{p}}{2 \tau_{y z}}=\frac{\dot{\gamma}_{z x}^{p}}{2 \tau_{z x}}
$$

where $\dot{\varepsilon}_{x}$ can be expressed in Equation (8):

$$
\dot{\varepsilon}_{x}=\left\{\sigma_{x}-\frac{1}{3}\left(\sigma_{x}+\sigma_{y}+\sigma_{z}\right)\right\} \dot{\lambda} .
$$

The $\dot{\varepsilon}_{\mathrm{y}}$ and $\dot{\varepsilon}_{\mathrm{z}}$ have similar equations. Similarly, the shear strain rate can be expressed as:

$$
\dot{\varepsilon}_{x y}=\frac{\dot{\gamma}_{x y}}{2}=\tau_{x y} \dot{\lambda}
$$

The $\dot{\varepsilon}_{\mathrm{yz}}$ and $\dot{\varepsilon}_{\mathrm{zx}}$ have similar equations. The scaling factor in Equations (8) and (9) can be derived from the work-hardening criterion as follows:

$$
\dot{\lambda}=\frac{3 \dot{\bar{\varepsilon}}}{2 \bar{\sigma}}
$$


where effective strain rate epsilon $\dot{\bar{\varepsilon}}$ is:

$$
\dot{\bar{\varepsilon}}=\sqrt{\frac{2}{3}\left\{\dot{\varepsilon}_{i j} \dot{\varepsilon}_{i j}\right\}} .
$$

\subsubsection{Constitutive Law}

The constitutive law of the material describes the relationship between the flow stress of the material and the plastic deformation, the strain rate, and the temperature, which can be summarized by the functional equation:

$$
\sigma=f(\dot{\varepsilon}, T)
$$

where $\sigma$ is the rheological stress in the plastic deformation process of material; $\dot{\varepsilon}$ is the strain rate; and $\mathrm{T}$ is the deformation temperature. Rheological stress can be calculated by the Zener-Hollomon formula. The specific expression is:

$$
\sigma(T, \dot{\varepsilon})=\sigma_{p} \sin h^{-1}\left[\left(\frac{Z}{A}\right)^{\frac{1}{n}}\right]
$$

where, $A, \sigma_{p}$, and $\mathrm{n}$ are the material parameters, and $\mathrm{Z}$ is the Zener-Hollomon parameter. The specific expression is:

$$
Z=\dot{\varepsilon} \exp \left(\frac{Q}{R T}\right)
$$

where $Q$ is the activation energy independent of temperature and $R$ is the gas constant. The specific parameters are shown in Table 2.

Table 2. 2024 aluminum alloy material parameters [36].

\begin{tabular}{cc}
\hline Parameter & Value \\
\hline $\mathrm{A}$ & $2.29 \times 10^{11} \mathrm{~s}^{-1}$ \\
$\mathrm{n}$ & 5.46 \\
$\mathrm{Q}$ & $178.0 \mathrm{~kJ} / \mathrm{mol}$ \\
$\sigma_{p}$ & $47.7 \mathrm{MPa}$ \\
$\mathrm{R}$ & $8.314 \mathrm{~J} / \mathrm{mol} \cdot \mathrm{K}$ \\
\hline
\end{tabular}

\subsection{Boundary Conditions}

\subsubsection{Thermal Boundary Condition}

The initial temperature of the workpiece, the tool, and the environment is defined as $25^{\circ} \mathrm{C}$. During the welding process, the heat transfer between the workpiece, tool, and the environment includes convection and radiation heat transfer, as shown in Equation (15). This heat transfer mode is defined on all surfaces except the root and butt surfaces of the workpiece. The heat transfer between the workpiece and the tool is defined as convective heat transfer, as shown in Equation (16). The heat transfer between the workpiece and the bottom plate is also defined as convection, as shown in Equation (17).

$$
\begin{gathered}
Q_{w a}=\sigma_{b} \varepsilon_{b}\left(T_{w}^{4}-T_{a}^{4}\right)+h_{a}\left(T_{w}-T_{a}\right) \\
Q_{w t}=K_{w t} \frac{\partial T}{\partial z}=h_{w t}\left(T_{w}-T_{t}\right) \\
Q_{w b}=K_{w b} \frac{\partial T}{\partial z}=h_{w b}\left(T_{w}-T_{b}\right)
\end{gathered}
$$




\subsubsection{Mechanical Boundary Condition}

All degrees of freedom of the workpiece are constrained to prevent rigid displacement and rotation of the workpiece during welding. Therefore, the velocity in the $\mathrm{z}$ direction of the bottom surface of the workpiece is defined to be 0 . The velocity in $\mathrm{x}$ and $\mathrm{y}$ directions on the side of the workpiece is 0 . The tool is defined to rotate around the z-axis in the positive direction-that is, counter-clockwise. When the welding is at the plunging stage, the speed of the tool is along the $\mathrm{z}$-axis. The speed of the tool is in the x-direction during welding.

\subsection{FEM Computational Mesh}

In the process of FSW, large plastic deformation occurs in the welding area, and the welding temperature field and stress and strain field change violently. In order to truly simulate the stirring action of the workpiece material in the welding process and visualize the plastic flow behavior of the material, the grid size of the welding seam area must be small enough. However, in the whole welding process, the welding parts are larger, and if the whole workpiece meshes with the same grid size, the calculation will be very large, which will seriously reduce the simulation efficiency. Therefore, in this model, the workpiece grid is divided into two types of grid: free quadrilateral grids used for welding plates, and free triangular grids used for the area around the stirring tool. In order to further reduce the calculation amount while ensuring the calculation accuracy, only the grid around the stirring tool is refined. In local grid refinement, through the absolute size control grid refinement of the grid size, the minimum grid size is set to $0.004 \mathrm{~mm}$, and the largest size is set to $1.4 \mathrm{~mm}$, so the accuracy of the grid is sufficient to reflect the plastic flow behavior of materials, the temperature field, and stress-strain field of the weld area. The grid size of the remaining area of the workpiece is set to $2.4 \mathrm{~mm}$ to improve computing efficiency. In this paper, the effect of the back plate on the workpiece is considered through mechanical and thermal boundary conditions, so the backing plate is not meshed to improve computing efficiency. The mesh partitioning of the model is shown in Figure 3.

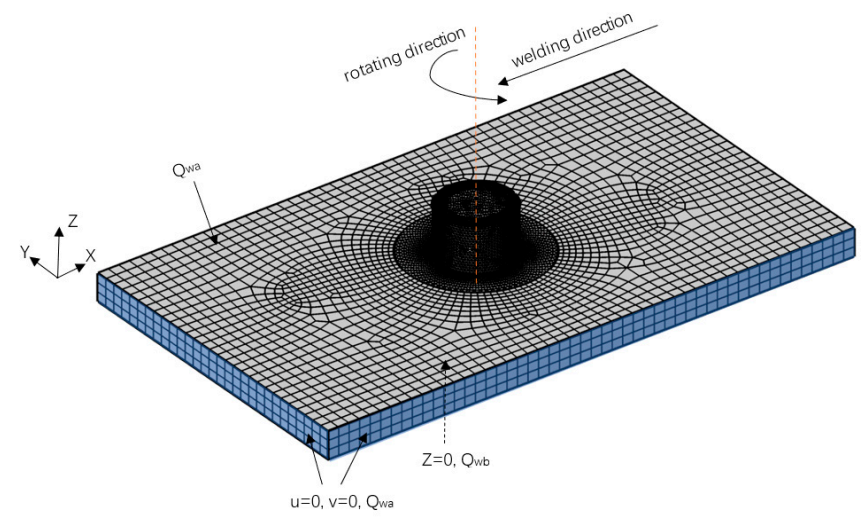

Figure 3. Mesh of the simulation domain.

\subsection{Model Validation}

To verify the established FSW model, a validation simulation was conducted according to the previous experiment [33]. In the validation simulation, the size of workpiece, technological parameters, and material are the same as those in the referenced experiment. The accuracy of the established FSW model was studied by comparing with the actual heat cycle curve of the measurement points located $8 \mathrm{~mm}$ from the weld center under different welding speeds. Figure 4 shows the heat cycle curve of experiment and simulation. By comparing the results between simulation and experiment, it can be seen that the heat cycle curves obtained by this model are basically consistent with those obtained by the actual welding test. Therefore, this model is accurate and feasible. 


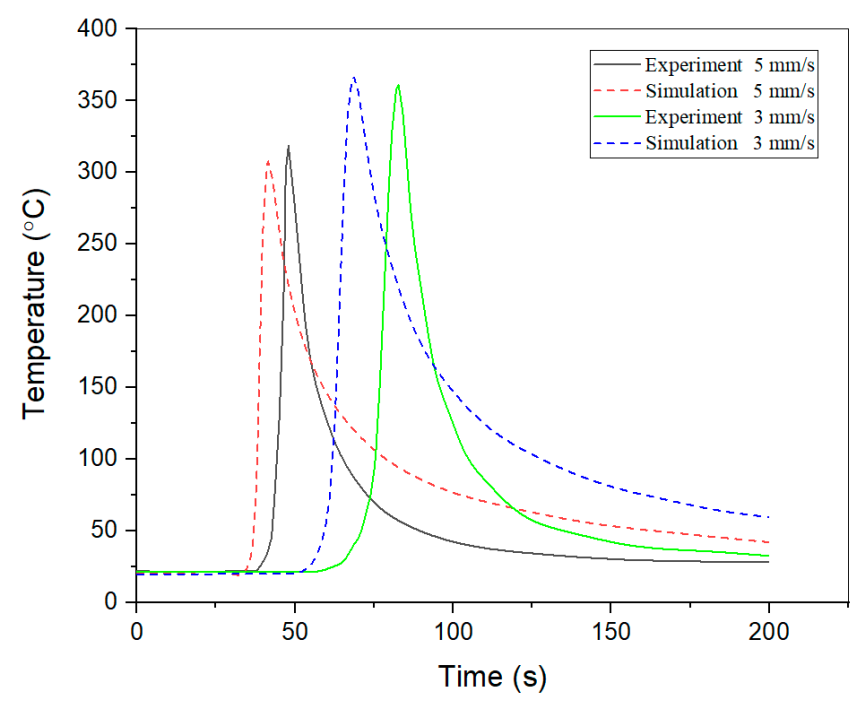

Figure 4. Comparison results of thermal cycling curves at different welding speeds obtained by simulation and experiment.

\section{Results and Discussions}

\subsection{Analysis of Fluidity at the Bottom of the Pin}

\subsubsection{Velocity Distribution}

Figure 5 shows the "S line" and non-penetration defect formed at the root of the weld due to insufficient plastic material flow. The material at the root of the weld can be divided into two different zones according to the flow behavior. As can be seen from Figure 5, at Zone I, the materials flow parallel to the bottom of the pin, and the materials on the advancing side (AS) and retreating side (RS) flow in the opposite direction and mix on the RS side. However, materials on both sides fail to be fully mixed, resulting in the appearance of a weak connection "S line" at the root of the weld. As for Zone II, near the weld center, all materials flow in the same direction (RS $\rightarrow$ AS), while almost all materials stop at the weld center, leading to the "vertical line" shape defect, i.e., non-penetration defect. In fact, the area under the pin bottom is called SWZ (the Swirl Zone) in Zeng's work [37], which refers to Zone I + Zone II in this paper. In their experimental research of the root flaws in a $6 \mathrm{~mm}$ 2014Al-T6 FSW joint under a pin length of $5.73 \mathrm{~mm}$, the "S line" defects appear at the weld root and extend to the stirring zone under a wide range of process parameters. The shape of the "S line" defects obtained in this paper in Figure 5 is similar with that observed in Figure 3 of Zeng's work. A similar root flaw was also observed in a $6 \mathrm{~mm}$ DH36 steel FSW joint under a pin length of $5.7 \mathrm{~mm}$ in Al-Moussawi's work [21].

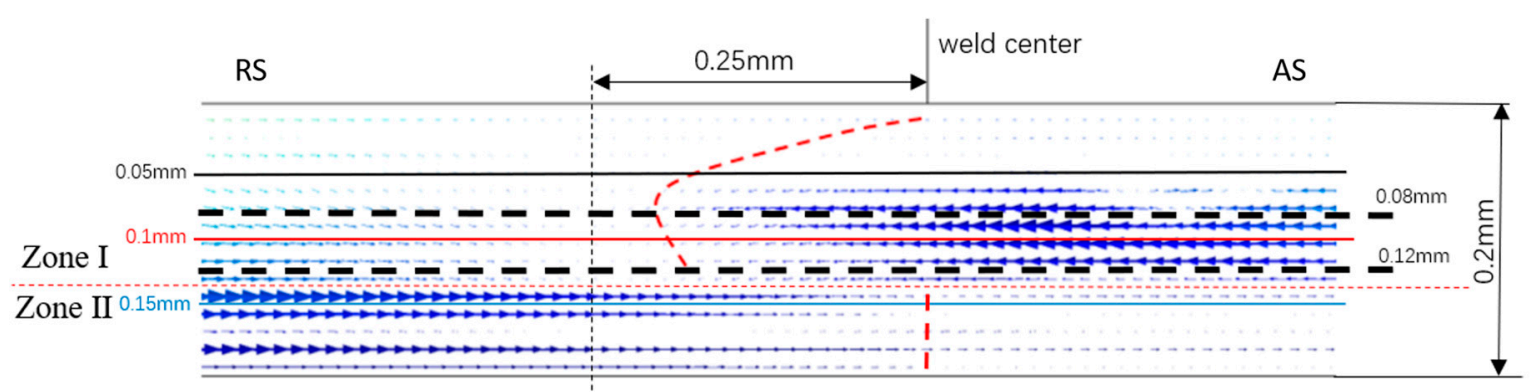

Figure 5. Simulation result of the plastic flow at the root of the weld. 
To explore the fluidity of plastic metal at the root of the FSW joint, the velocity distribution of the plastic material in Figure 5 was measured under different depths $(0.05,0.1$, and $0.15 \mathrm{~mm}$ under the pin). Figure $6 \mathrm{a}-\mathrm{c}$ shows the measurement results for the velocity distribution in the $\mathrm{x}, \mathrm{y}$, and $\mathrm{z}$-directions, respectively. The horizontal axis represents the distance to the center of the weld, in which the positive axis is AS, the negative axis is RS, and the vertical axis represents the partial velocity.

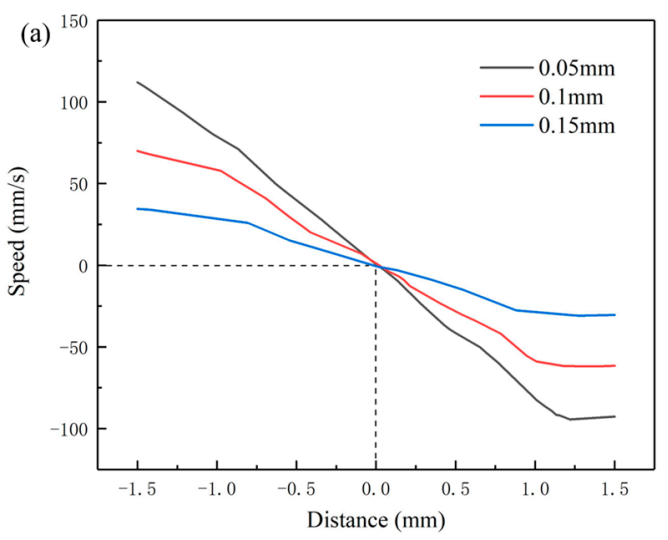

(a)

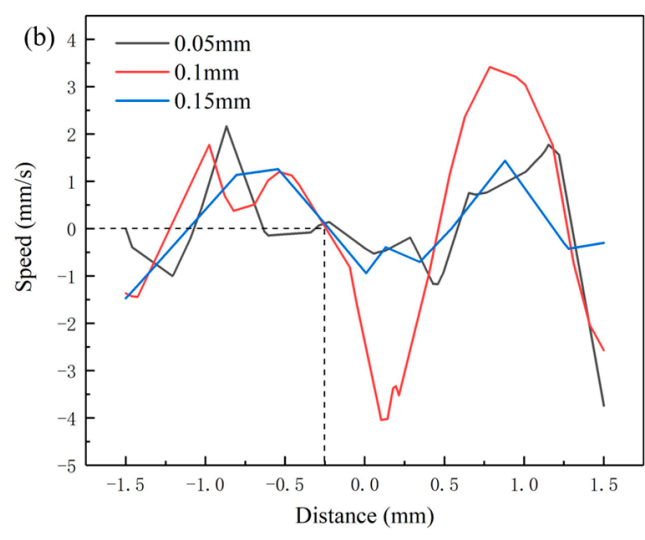

(b)

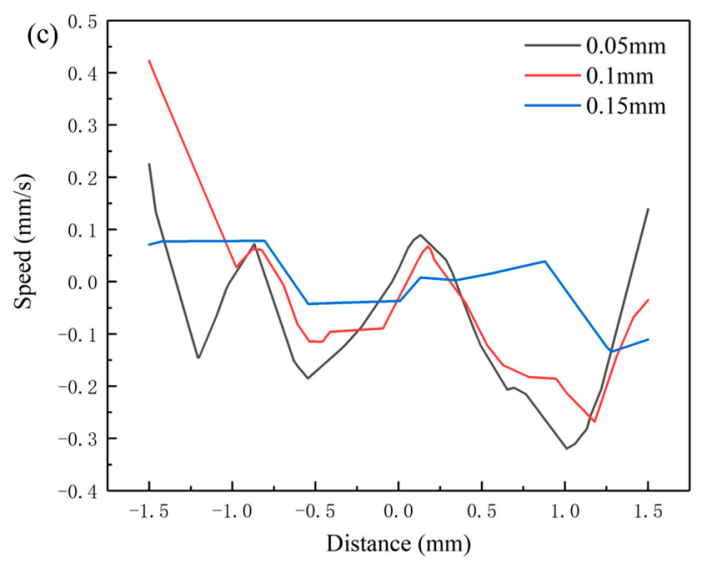

(c)

Figure 6. Speed curves of different distances from the bottom of the pin $(1000 \mathrm{rpm}, 120 \mathrm{~mm} / \mathrm{min}, 5.8 \mathrm{~mm}$ pin length). (a) Velocity in the $\mathrm{x}$-direction; (b) velocity in the $\mathrm{y}$-direction; (c) velocity in the $\mathrm{z}$-direction.

In Figure 6a, it can be seen from the figure that the velocity of the plastic metal in the $x$-direction takes the center of the weld $(\mathrm{y}=0)$ as the boundary line, advancing side (AS) plastic metal flows in the welding direction $(\mathrm{v}<0)$, and retreating side $(\mathrm{RS})$ plastic metal flows in the opposite direction of the welding $(\mathrm{v}>0)$. The closer it is to the end face of the pin $(0.05 \mathrm{~mm})$, the better the fluidity of the plastic metal in the $x$-direction and the faster the flow speed.

As can be seen in Figure $6 \mathrm{~b}$, near $0.25 \mathrm{~mm}$ from the weld center on the RS side, the transverse flow velocity at different depths is close to 0 , indicating that the plastic flow in this area is poor. As a result, weak connection defects can easily form near the center line of the weld due to insufficient material fluidity. However, at the middle position between the end of the pin and the bottom of the workpiece $(0.1 \mathrm{~mm})$, the fluidity is relatively good. AS and RS plastic metal move in the opposite direction toward the center of the weld line and meet at RS $(x=-0.25)$.

In addition, the maximum velocity of the plastic metal at the root of the weld is only $0.45 \mathrm{~mm} / \mathrm{s}$ in the depth direction ( $\mathrm{z}$ direction), as shown in Figure $6 \mathrm{c}$. Therefore, the plastic metal at the root of the weld basically has almost no flow in the depth direction. It can also be found that the velocity distribution in Zone II is always the smallest in three directions compared with zone I, indicating the poorer fluidity of material in Zone II. 


\subsubsection{Driving Force Distribution}

At the bottom of the pin, the pressure between the plastic metal is an important driving force for the flow of the plastic metal. Furthermore, the shear action of the tool against the plastic metal is also one of the driving forces for the flow of the plastic material. Therefore, the combined effect of pressure and shear stress on the plastic material directly affects the fluidity of the material. In order to investigate the distribution of the pressure and shear stress, a series of measurement points were set at the bottom of the pin, as shown in Figure 7. In Figure 7, the distance from the end face of the pin is $0.02 \mathrm{~mm}, 0.05 \mathrm{~mm}, 0.08 \mathrm{~mm}, 0.1 \mathrm{~mm}, 0.12 \mathrm{~mm}, 0.15 \mathrm{~mm}$, and $0.18 \mathrm{~mm}$, respectively.

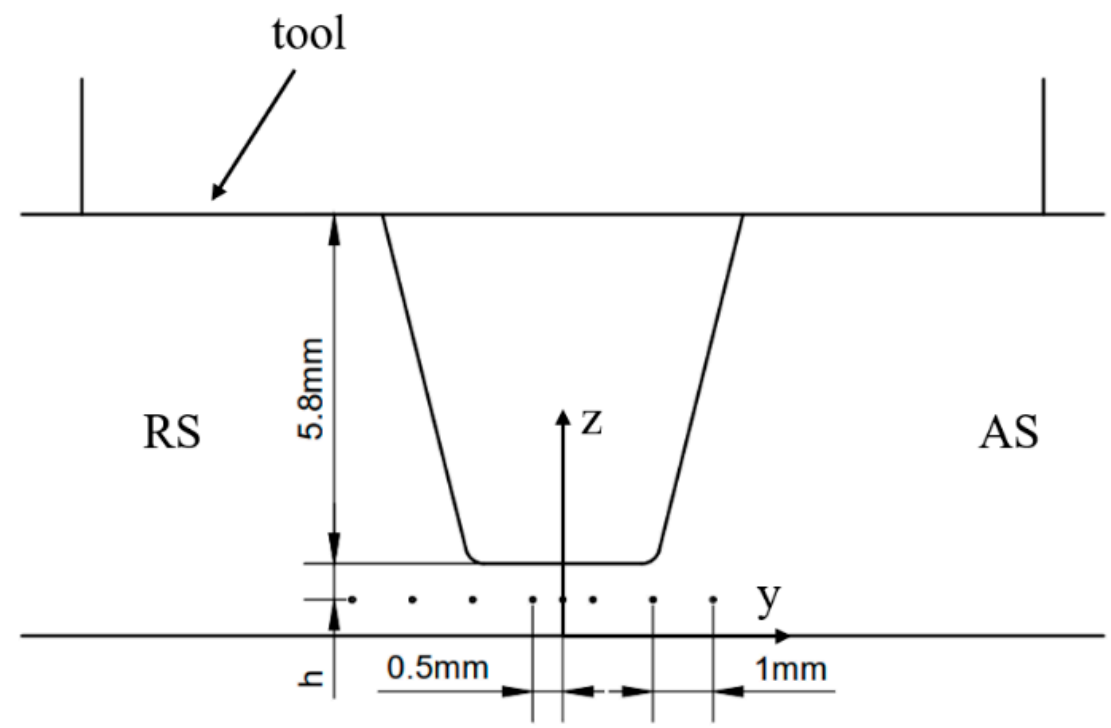

Figure 7. Distribution of test points at the root of the weld.

Figure 8 a shows the distribution of pressure at the root of the weld. In Figure 8, as the depth increases, the pressure reduces. Furthermore, there is a low-pressure zone near the center line on the RS side, and the lowest pressure is reached at $y=-0.5$. The uneven distribution of pressure near the center line causes the plastic metal to flow from both sides of AS and RS to the center of the weld, which is consistent with the velocity distribution in Figure 5. However, at the low-pressure zone, the pressure is not enough to fully mix the material from both sides of AS and RS, leading to the weak connection.

Figure $8 \mathrm{~b}$ shows the distribution of shear stress at the root of the weld. In Figure $8 \mathrm{~b}$, near the weld center line $(y=0)$, it can be found that the shear stress is close to 0 when the distance from the bottom surface of the pin is too short $(0.02-0.05 \mathrm{~mm})$ or too long $(0.15-0.18 \mathrm{~mm})$. However, when the distance is moderate $(0.08-0.12 \mathrm{~mm})$, the shear stress reaches a relatively high level. Therefore, plastic metal near the bottom surface of the pin and the bottom surface of the workpiece has poor fluidity, while the plastic metal between these has strong fluidity. According to Figure 5, it can be found that the location of the left-leaning line of the "S line" is at the depth of $0.08-0.12 \mathrm{~mm}$, and this is consistent with the depth range of the high shear stress, which indicates that the formation of the left-leaning line is related to the change of the shear stress. In Figure 8c, it can also be found that the difference of shear stress between $y=-0.5$ and $y=0$ is smaller when the depth is in the range of $0.08-0.12 \mathrm{~mm}$. Furthermore, combined with Figure $8 \mathrm{a}, \mathrm{b}$ and Figure 5, it can be found that at the Zone II $(\mathrm{h}>0.15 \mathrm{~mm})$, the pressure and shear stress are relatively lower than that at Zone I, which is consistent with the velocity distribution at Zone II, as shown in Figure 5. 


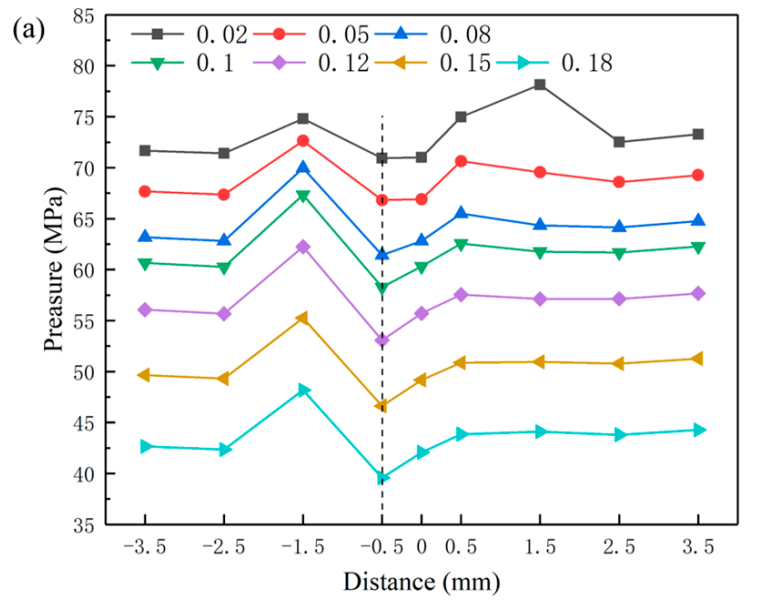

(a)

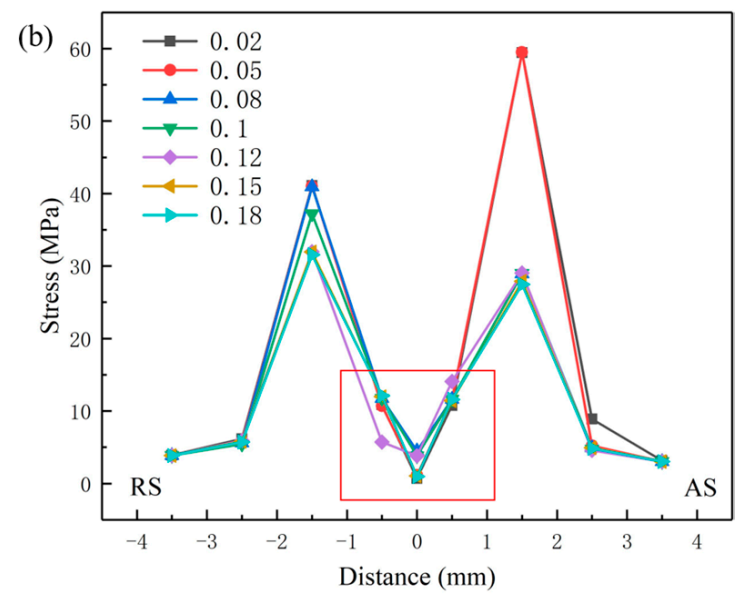

(b)

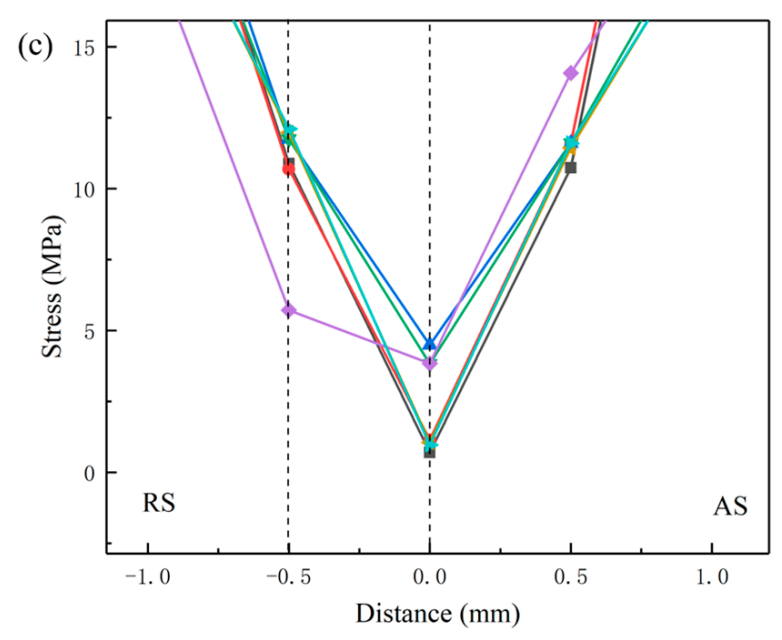

(c)

Figure 8. Distribution of the driving force at a different distances from the end face of the pin (1000 rpm, $120 \mathrm{~mm} / \mathrm{min}$ ). (a) Pressure distribution; (b) shear stress distribution; (c) partial enlargement of (b).

\subsection{Effect of Pin Length on the Formation of Root Flaw}

\subsubsection{Effect of Pin Length on the Material Flow}

In order to solve the defects of a weak connection and non-penetration at the root of FSW joints of aluminum alloy, the relationship between welding allowance and root flaws was investigated. Figure 9 shows the velocity distribution under a pin length of 5.8, 5.85, 5.9, 5.95, and $6.0 \mathrm{~mm}$, respectively. Figure 10 shows the velocity distribution in the y-direction at the half depth between the bottom surface of the pin and the bottom surface of the workpiece.

When the length of the pin is $5.8 \mathrm{~mm}$ or $5.85 \mathrm{~mm}$, the "S line" defect appears at the root of the FSW weld seam, as shown in Figure 9a,b. As the pin length increases to $5.9 \mathrm{~mm}$, the "S line" shape defect changes to the "right-tilting line" shape defect (Figure 9c), and finally the "S line" defect is eliminated when the pin length is $5.95 \mathrm{~mm}$ (Figure 9d). In Figure 10, as the pin length increases from 5.8 to $5.95 \mathrm{~mm}$, the velocity difference between RS and AS near the weld center (Figure 10 mark I, II) becomes larger, which indicates a larger driving force, leading to the material being more fully mixed near the weld center. 
(a)
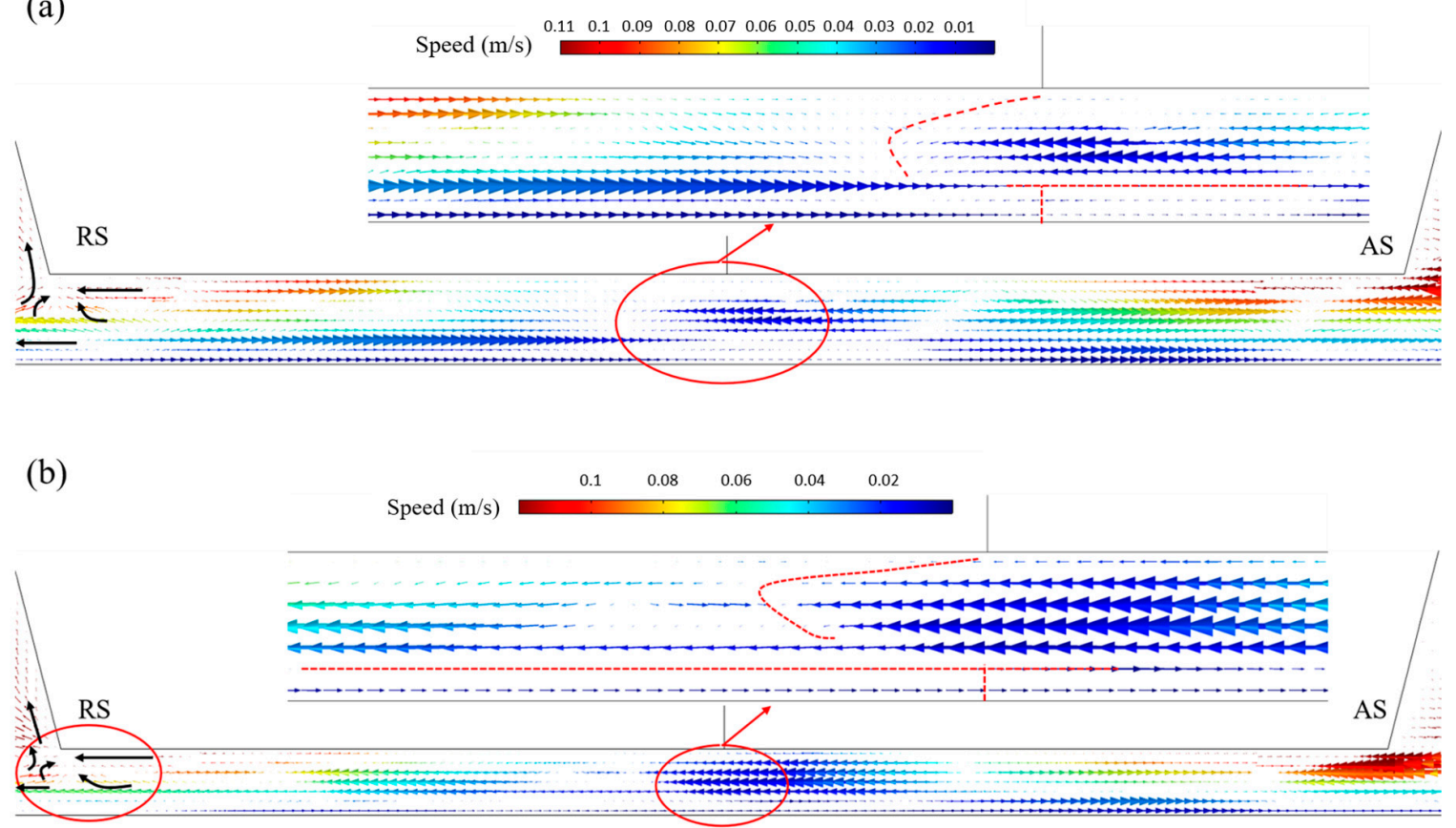

(c)
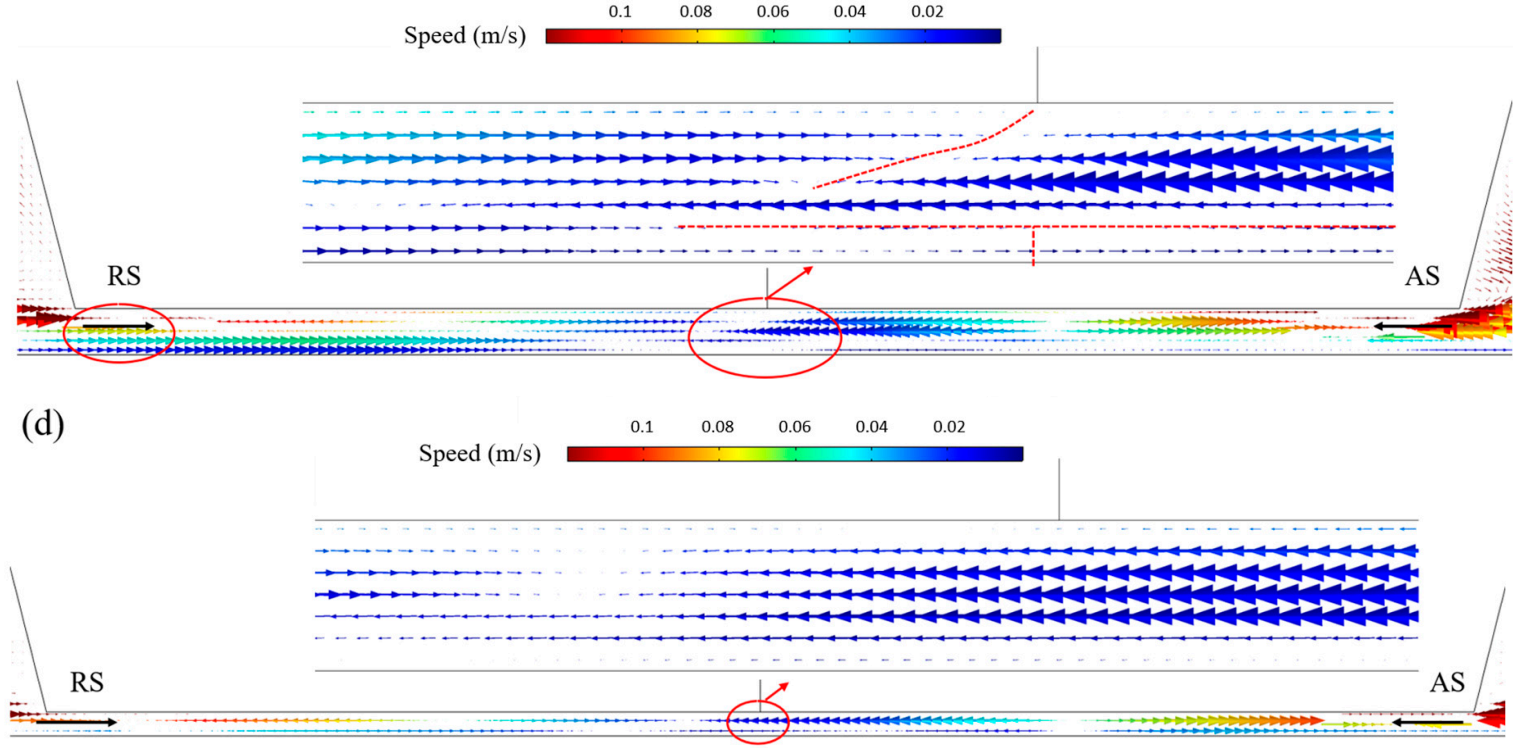

(e)

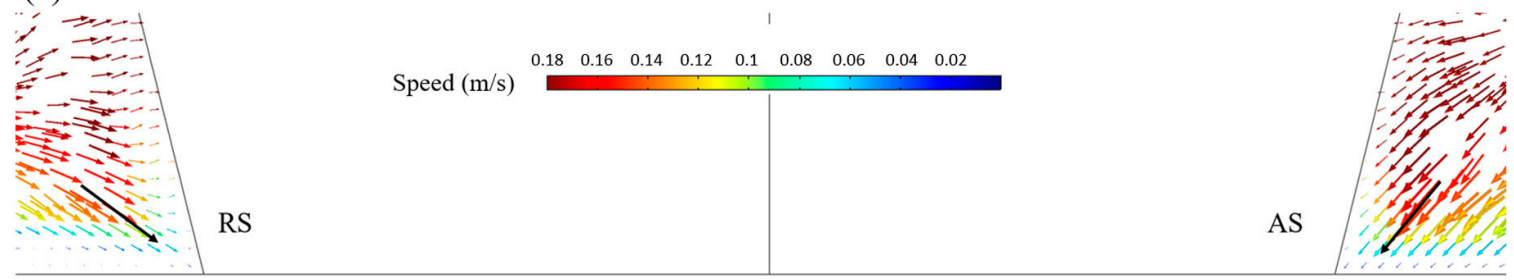

Figure 9. Effect of pin length on plastic metal flow at the root of the weld (1000 rpm, $120 \mathrm{~mm} / \mathrm{min}$ ). (a) $5.8 \mathrm{~mm}$; (b) $5.85 \mathrm{~mm}$; (c) $5.9 \mathrm{~mm}$; (d) $5.95 \mathrm{~mm}$; (e) $6.0 \mathrm{~mm}$. 


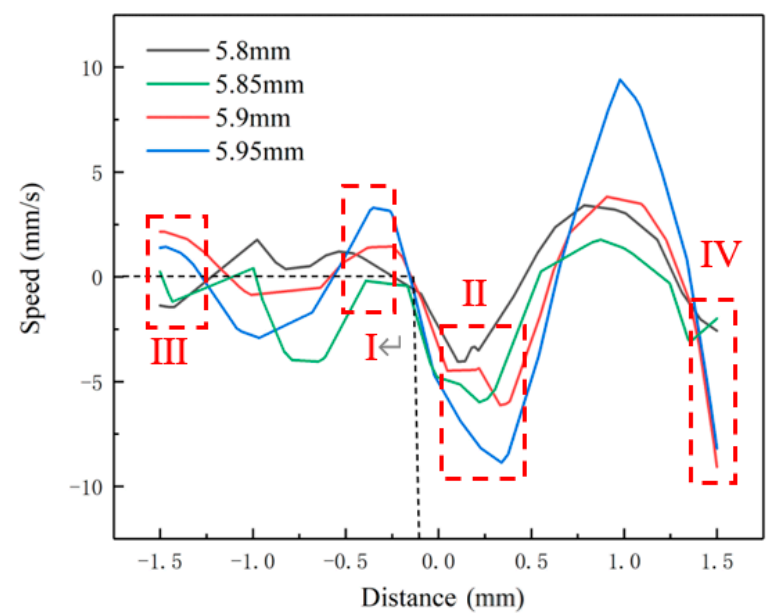

Figure 10. Velocity distribution in the y-direction in Figure 5 (1000 rpm, $120 \mathrm{~mm} / \mathrm{min}, 5.8 \mathrm{~mm}$ pin length).

It should be noted that the material flow formation near the weld center changes when the pin length increases. When the pin length increases from 5.8 to $5.85 \mathrm{~mm}$, near the weld center, the material flow direction changes from RS $\rightarrow$ AS to AS $\rightarrow$ RS under the "S line", which causes more material transfer from AS to RS, and the "S line" further extends to the RS side. When the pin length increases to $5.9 \mathrm{~mm}$, the "S line" changes to the "right-tilting line", because the material on the right side of "left-tilting line" all flows to the RS side. Finally, the material on the right side of the "right-tilting line" all flows to the RS side, and the defect-free welded joint is obtained when the pin length is $5.95 \mathrm{~mm}$.

On the other hand, the material flow form on the margin of the pin also significantly changes when the pin length increases. As the pin length increases from 5.85 to $5.9 \mathrm{~mm}$, the material flow on the left margin of the pin changes from vortex flow (marked red circle in Figure $9 b$ ) into the transverse flow (marked red circle in Figure 9c), and the flow direction changes from left to right, which can also be observed in Figure 10 mark III. It can also be found that the material flow form on the right margin of the pin remains in transverse flow when the pin length increases, while the velocity increases significantly as shown on the mark IV in Figure 10.

When the pin length is equal to the thickness of the workpiece, there is no welding allowance, and the welding plate does not exist in weak connections and non-penetration defects; as can be seen from Figure 9e, the plastic materials on both sides flow to the root of the weld. In this case, the pin directly contacts with the backing plate, which is easy to weld the workpiece together with the working table, and the bottom of the welding plate is poorly formed. Therefore, zero welding allowance is not recommended in practical production.

When the pin length is $5.9 \mathrm{~mm}$, there is still a weak connection and non-penetration defects at the root of the weld. Therefore, the plastic metal flow behavior near the root of the weld center was investigated in detail when the pin length was 5.91-5.95 mm, as shown in Figure 11. When the pin length increases from 5.91 to $5.93 \mathrm{~mm}$, the "S line" defects (red dashed line in the Figure 11) and non-penetration defects still exist. It should be noted that with the increase of the pin length, the width of the "S line" and the angle between the tangent line of the "S line" and the bottom surface of pin gradually reduces, as shown in Figure 11a-c, which may be attributed to the increased shear stress (see the Section 3.2.3) and speed difference between the RS and AS sides near the weld center (Figure 12 mark I, II). When the pin length increases to $5.94 \mathrm{~mm}$ (Figure 11d), the plastic metal flows through the center line under the end surface of the pin, which eliminates the "S line" defect. However, the fluidity near the bottom surface of the weld is still insufficient, so that the non-penetration defect still exists. The non-penetration defect is finally eliminated when the pin length is increased to $5.95 \mathrm{~mm}$ (Figure 11e). 

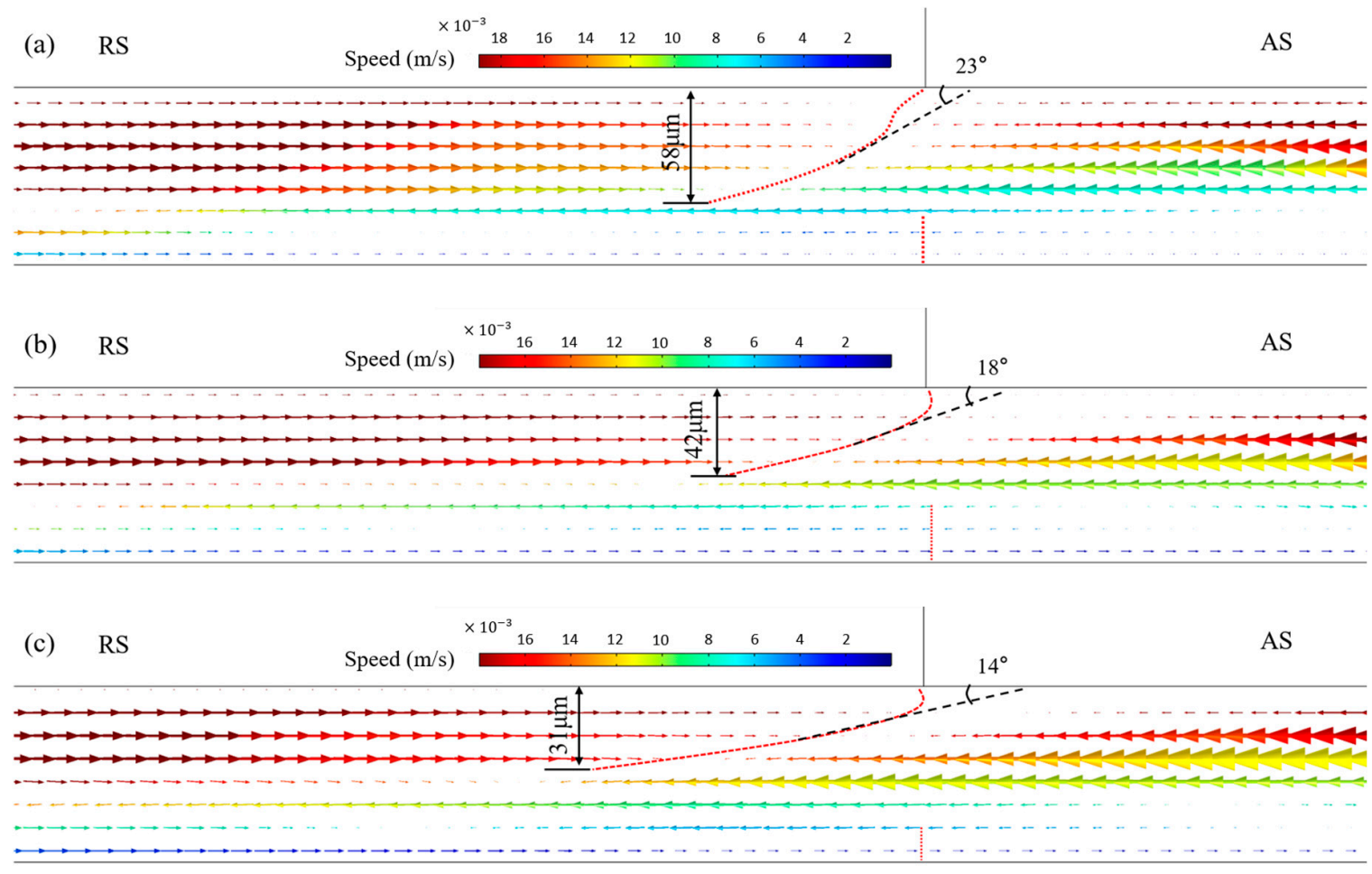

(d) $\mathrm{RS}$ Speed $(\mathrm{m} / \mathrm{s})$

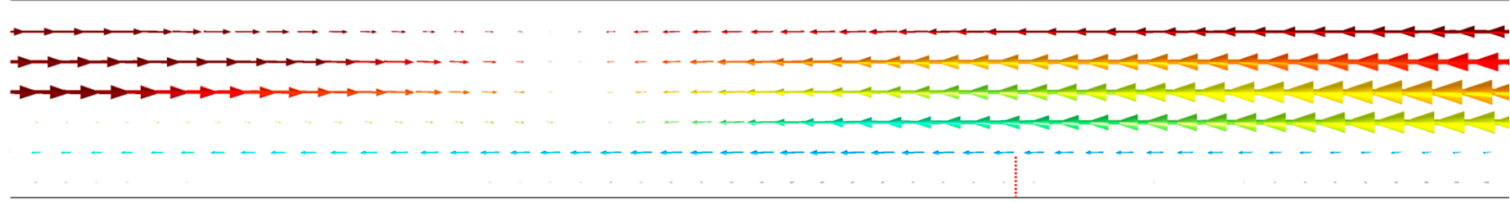

(e) RS Speed $(\mathrm{m} / \mathrm{s})$

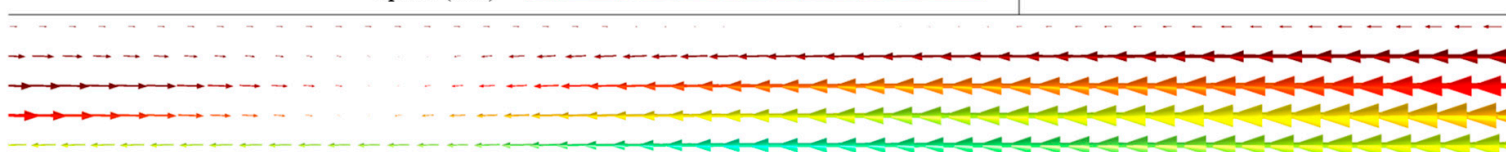

Figure 11. Influence of root welding allowance on plastic metal flow behavior at the root of the welding seam (1000 rpm, $120 \mathrm{~mm} / \mathrm{min}$ ). (a) $0.09 \mathrm{~mm}$; (b) $0.08 \mathrm{~mm}$; (c) $0.07 \mathrm{~mm}$; (d) $0.06 \mathrm{~mm}$; (e) $0.05 \mathrm{~mm}$.

\subsubsection{Effect of Pin Length on the Heat Input}

Figure 13 shows the temperature of the top and bottom surface of the weld under different pin lengths. It is obvious from the figure that the welding heat input is basically unchanged when the pin length changes in a small range $(0.2 \mathrm{~mm})$. Therefore, the temperature of the plastic metal at the root of the weld is basically unchanged when welding with different lengths of the pin.

We continually increased the length of the pin by a step of $0.01 \mathrm{~mm}$ and studied the plastic metal flow at the bottom of the weld with the length of the pin at $5.96 \mathrm{~mm}, 5.97 \mathrm{~mm}, 5.98 \mathrm{~mm}$, and $5.99 \mathrm{~mm}$. Figure 14 shows the temperature field distribution of the weld cross-section when the pin length exceeds $5.95 \mathrm{~mm}$. As can be seen from the Figure 14, when the pin length is $5.95 \mathrm{~mm}$, the highest temperature of the weld $\left(423^{\circ} \mathrm{C}\right)$ appears on the upper surface of the weld, as shown in Figure 14a. However, when the pin length is greater than $5.95 \mathrm{~mm}$, the maximum temperature of the weld appears at the center of the bottom of the weld. When the pin length increases from $5.96 \mathrm{~mm}$ to $5.99 \mathrm{~mm}$, 
the maximum temperature increases from 439 to $481^{\circ} \mathrm{C}$, as shown in Figure $14 \mathrm{~b}-\mathrm{e}$ [38]. As aluminum alloy is a low-melting alloy, if the weld temperature is too high, the recrystallization of the weld will be coarsened. According to the Hall-Petch principle, the coarsening of the weld will reduce the joint strength.

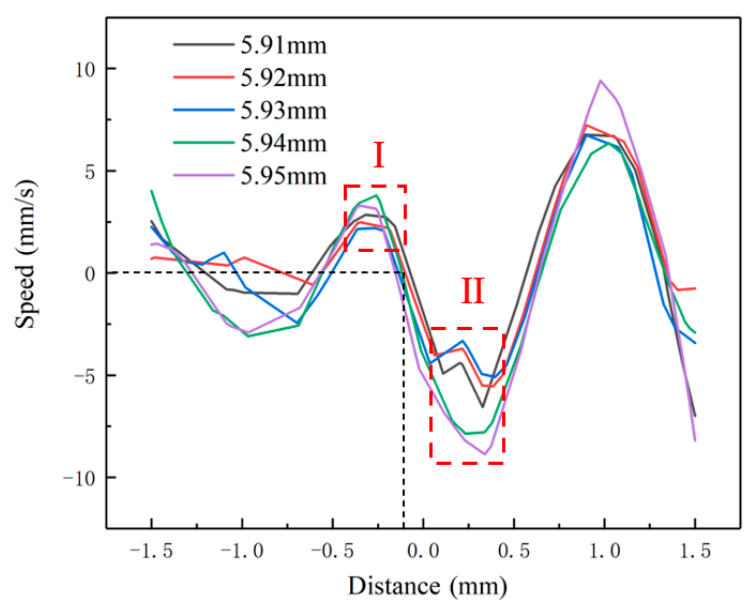

Figure 12. Flow velocity curves of plastic metal at the root of joint with different pin lengths (1000 rpm, $120 \mathrm{~mm} / \mathrm{min}$ ). (a) $0.05 \mathrm{~mm}$ per step from $5.8 \mathrm{~mm}$ to $5.95 \mathrm{~mm}$; (b) $0.01 \mathrm{~mm}$ per step from $5.91 \mathrm{~mm}$ to $5.95 \mathrm{~mm}$.

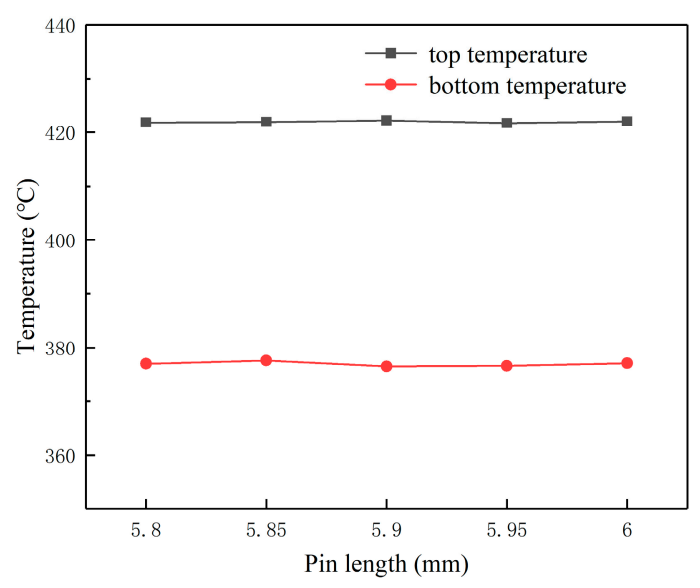

Figure 13. Influence of pin length on temperature field of the top and bottom surface of the weld (1000 rpm, $120 \mathrm{~mm} / \mathrm{min})$.

Although the temperature at the bottom of the weld increases with the increase of the length of the pin, when the length of the pin exceeds $5.95 \mathrm{~mm}$, the flow velocity of the plastic metal at the bottom of the weld does not increase accordingly, as shown in Figure 15 (within the two black dashed lines). At the center of the weld, the flow rate of the plastic metal is basically the same, about $5 \mathrm{~mm} / \mathrm{s}$. Therefore, when the length of the pin exceeds $5.95 \mathrm{~mm}$, further increasing the length of the pin will not improve the flow capacity of the plastic metal at the bottom of the joint, but it will sharply increase the temperature at the bottom of the weld, leading to the coarsening of the recrystallization tissue and the reduction of the joint strength. On the other hand, if the pin is too long, it will pass through the whole thickness of the workpieces and directly contact with the hard backing plate or the FSW machine substrate. In the friction stir welding process, the two will produce intense friction and wear, resulting in the rapid damage of the pin and the FSW machine substrate. At the same time, the pin itself also changes significantly in length, shape, and structure due to rapid friction and wear, and the stable FSW welding process becomes difficult to control, which leads to the deterioration of welding forming and affects the quality of welded joints greatly. Therefore, for $6 \mathrm{~mm}$ thick 2024 aluminum 
alloy, a $5.95 \mathrm{~mm}$ pin is most suitable for welding, which can eliminate the "S line" and non-penetration defects at the bottom of the welding seam.

(a)

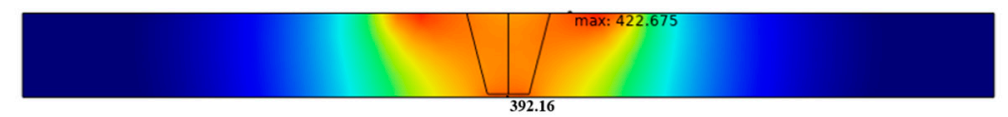

(b)

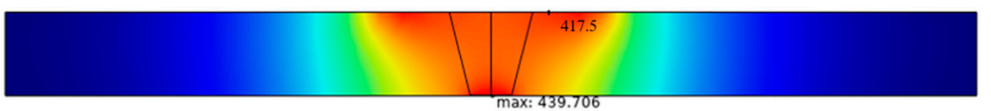

(c)

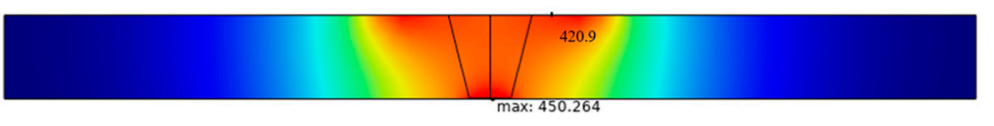

Temperature $\left({ }^{\circ} \mathrm{C}\right)$

(d)

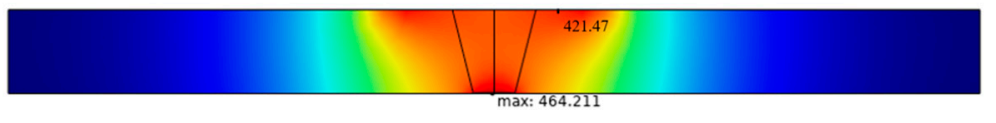

(e)

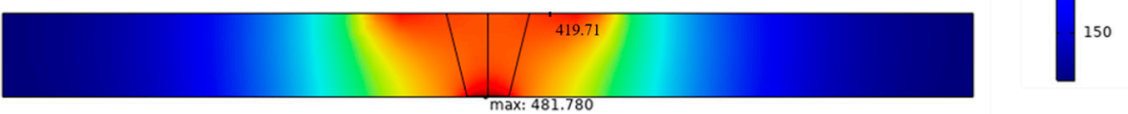

Figure 14. Temperature field of weld cross-section at different lengths of pin $(1000 \mathrm{rpm}, 120 \mathrm{~mm} / \mathrm{min}$, $6 \mathrm{~mm}$ thick workpiece) (a) $5.95 \mathrm{~mm}$; (b) $5.96 \mathrm{~mm}$; (c) $5.97 \mathrm{~mm}$; (d) $5.98 \mathrm{~mm}$; (e) $5.99 \mathrm{~mm}$.



Figure 15. Distribution curve of flow velocity of plastic metal at the bottom of weld seams with different lengths of pin (1000 rpm, $120 \mathrm{~mm} / \mathrm{min})$.

In fact, studying the different pin lengths is not only necessary for the engineering design and use of the stirring pin; more importantly, the pin length itself is varied in the actual FSW process owing to the wear of the stirring pin. Hence, the material flow behavior under the pin bottom is also influenced by the change of pin length. Therefore, studying the different pin lengths is to consider the inevitable wear of the stirring pin in the actual FSW process and its effect on the formation of the FSW joint, which is of great significance. The issues related to the wear of the stirring pin will be discussed in our research work and papers in the future.

\subsubsection{Effect of Pin Length on Stress Field}

Although slight adjustment of the length of the pin can increase the temperature of the weld root, it has little effect on the improvement of material fluidity near the weld center, as outlined in Section 3.2.2. However, the shear action of stirring on plasticized metal will change as the length of the pin increases, as shown in Figure 16. At the root of the weld, the shear stress near the center of the weld is the lowest, which indicates that the plastic metal flow in this area is the weakest. When the length of 
the pin is increased from $5.91 \mathrm{~mm}$ to $5.95 \mathrm{~mm}$ with $0.01 \mathrm{~mm}$ per step, the shear effect of stirring on the plastic metal at the root of the weld would be gradually strengthened. Therefore, the fluidity of the plastic metal at the root of the weld also increases, which results in the gradual improvement of the forming quality at the root of the weld. When the length of the pin was $5.95 \mathrm{~mm}$, a weld without root defects could be obtained.
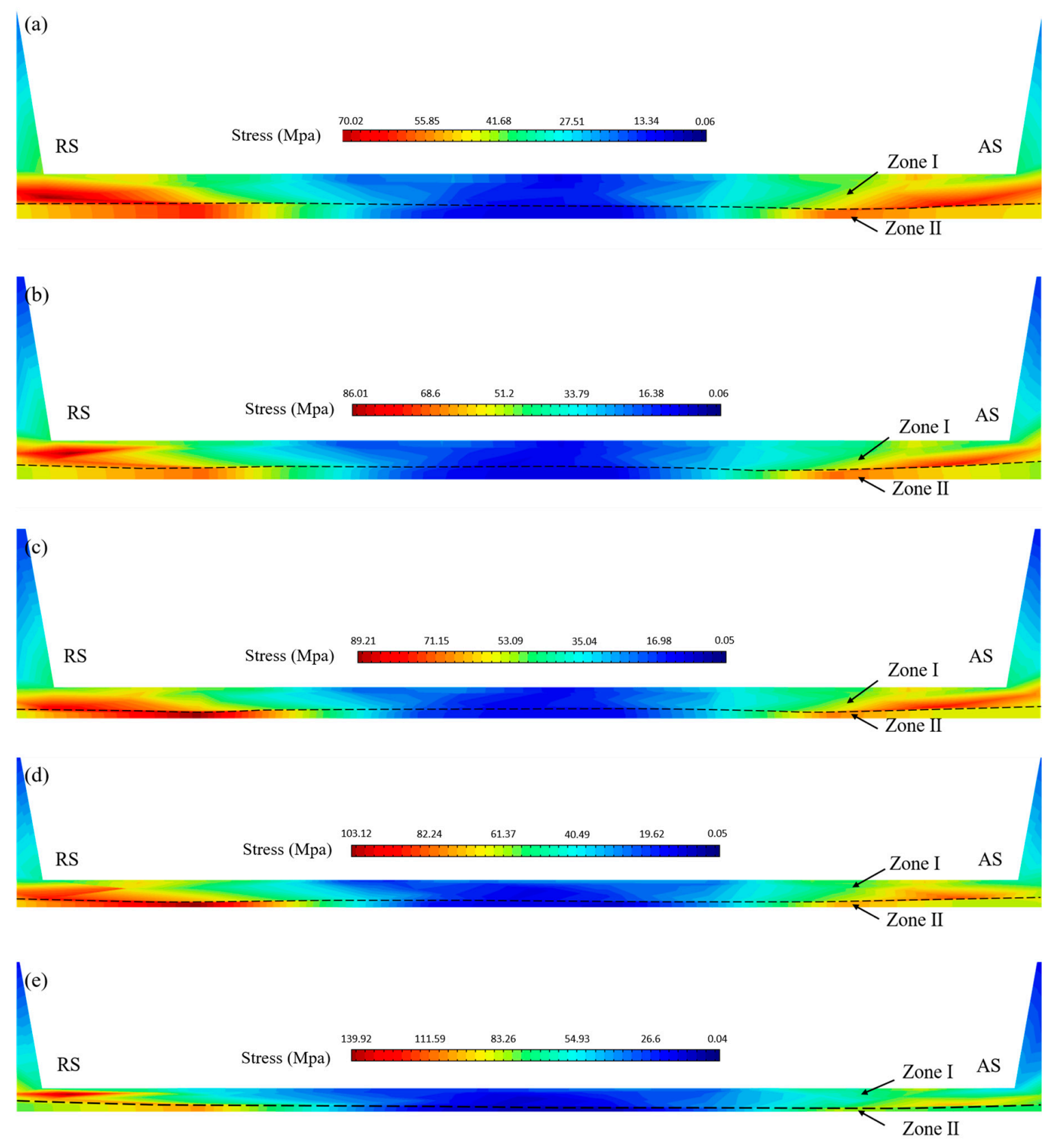

Figure 16. Distribution of shear stress at the root of the joint at different pin lengths (1000 rpm, $120 \mathrm{~mm} / \mathrm{min}$ ). (a) $5.91 \mathrm{~mm}$; (b) $5.92 \mathrm{~mm}$; (c) $5.93 \mathrm{~mm}$; (d) $5.94 \mathrm{~mm}$; (e) $5.95 \mathrm{~mm}$.

It should be noted that there is a sharp transition of the shear stress near the bottom surface of the workpiece, as shown by the black dash line in Figure 16. The sharp transition of the shear stress illustrates that the material flow behavior in zones I and II (marked in Figure 16a) is different. In fact, this can be explained by the difference of the constraint condition and the driving force of the material in zones I and II. In zone I, the material is constrained by the bottom surface of the pin and the material in zone II. The material flow in zone I is driven by the rotation of the bottom 
surface of the pin, and the pressure and shear stress are all higher in zone I according to Figure 8a,b. Meanwhile, in zone II, the material is constrained by the bottom surface of the workpiece and the material in zone I. The material flow in zone II is driven by the material flow in zone I, and the pressure and shear stress are lower than that in zone I according to Figure $8 \mathrm{a}, \mathrm{b}$, resulting in a slower velocity in zone II, which is consistent with the velocity distribution in Figure 6b. Therefore, non-penetration defects easily generate near the weld center in zone II due to the poorest fluidity and no material mixing in this area. With the increase of the pin length, the thickness of the zone II reduces, and it is close to 0 near the weld center when the pin length increases to $5.95 \mathrm{~mm}$, so that the non-penetration defect is eliminated.

Figure 17 shows the distribution curve of shear stress at the half depth between the bottom surface of the pin and the bottom surface of the workpiece under different pin lengths. In Figure 17a, when the pin length increases from 5.8 to $5.95 \mathrm{~mm}$ with $0.05 \mathrm{~mm}$ per step (Figure 17a), the shear stress on the RS side near the weld center $(-0.5<\mathrm{y}<0)$ significantly increases, which makes the material mixed more fully in this area where the "S line" defect appears. A similar trend can be observed as the pin length increases from 5.9 to $5.95 \mathrm{~mm}$ with $0.01 \mathrm{~mm}$ per step, as shown in Figure $17 \mathrm{~b}$. As the length of the pin changes, it should be some relationship between the increasing shear stress (Figure $17 \mathrm{~b}$ ) and the morphotype of the "S line" shown in Figure 11a-c. That is to say, in Figure 17b, as the shear stress gradually increases with the increase of pin length, the width and the tilting angle of "S line" gradually reduces according to Figure $11 \mathrm{a}-\mathrm{c}$, which also indicates that the shear stress plays a dominant role in eliminating the "S line" defect.
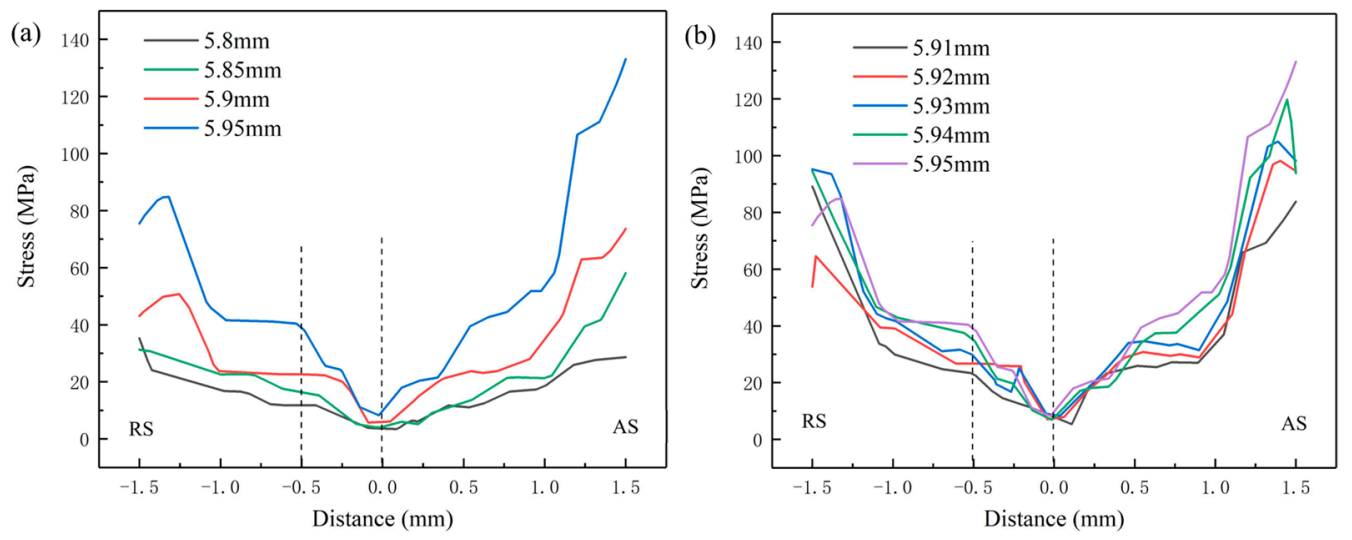

Figure 17. Distribution curves of shear stress at the root of joint with different pin lengths (1000 rpm, $120 \mathrm{~mm} / \mathrm{min}$ ). (a) $0.05 \mathrm{~mm}$ per step from 5.8 to $5.95 \mathrm{~mm}$; (b) $0.01 \mathrm{~mm}$ per step from 5.91 to $5.95 \mathrm{~mm}$.

External cooling was applied to the bottom of the workpiece to reduce the bottom temperature of the weld and explore the plastic metal flow behavior at the bottom of the weld at different temperatures. In order to change the temperature of the plastic metal at the bottom of the weld, five groups of simulations were carried out to cool the weld floor. The temperature change curve of the bottom of the weld is given in Figure 18. At the welding parameters of $1000 \mathrm{rpm}$ and $120 \mathrm{~mm} / \mathrm{min}$, the temperature at the bottom of the weld gradually decreased from 377 to $302{ }^{\circ} \mathrm{C}$, and the plastic metal flow behavior at the bottom of the weld was observed. The flow behavior of plastic metal at the bottom of the weld is shown in Figure 19. When the temperature at the bottom of the weld changes, the fluidity of the plastic metal in the weld basically does not change. Near the center of the pin bottom, plastic metal has little flow. With the increase of the distance to the end face of the pin bottom, the flow of plastic metal gradually increases. RS and AS plastic metal flow in the opposite direction and finally meet at the RS near the weld center. At the bottom of the weld, plastic metal flows from RS to AS, and the plastic metal flow basically stops near the center of the weld. Based on the above flow behavior, the plastic metal at the bottom of the weld will eventually form the "S line" weak connection defect and lack penetration at the center of the bottom of the weld. 


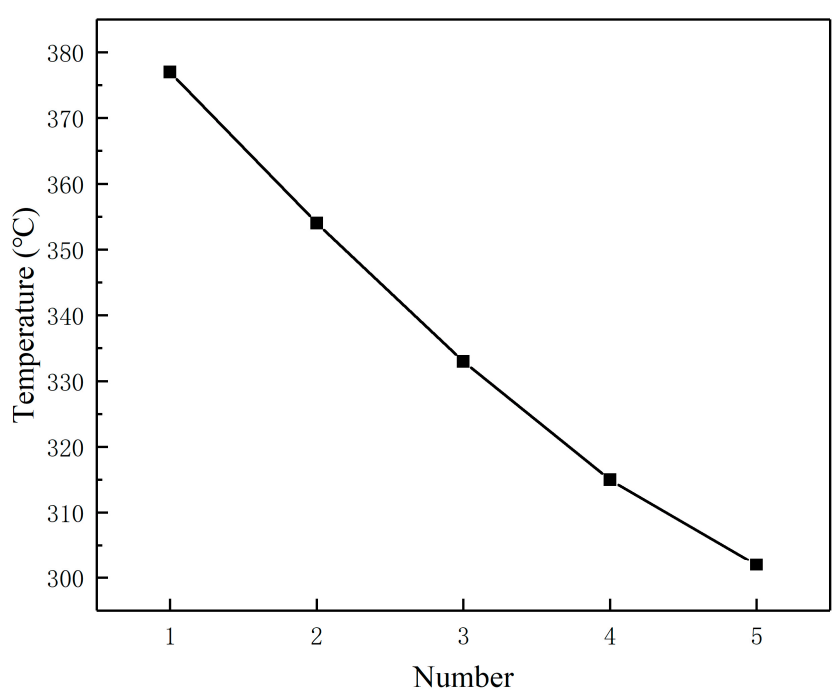

Figure 18. Weld bottom temperature curve.
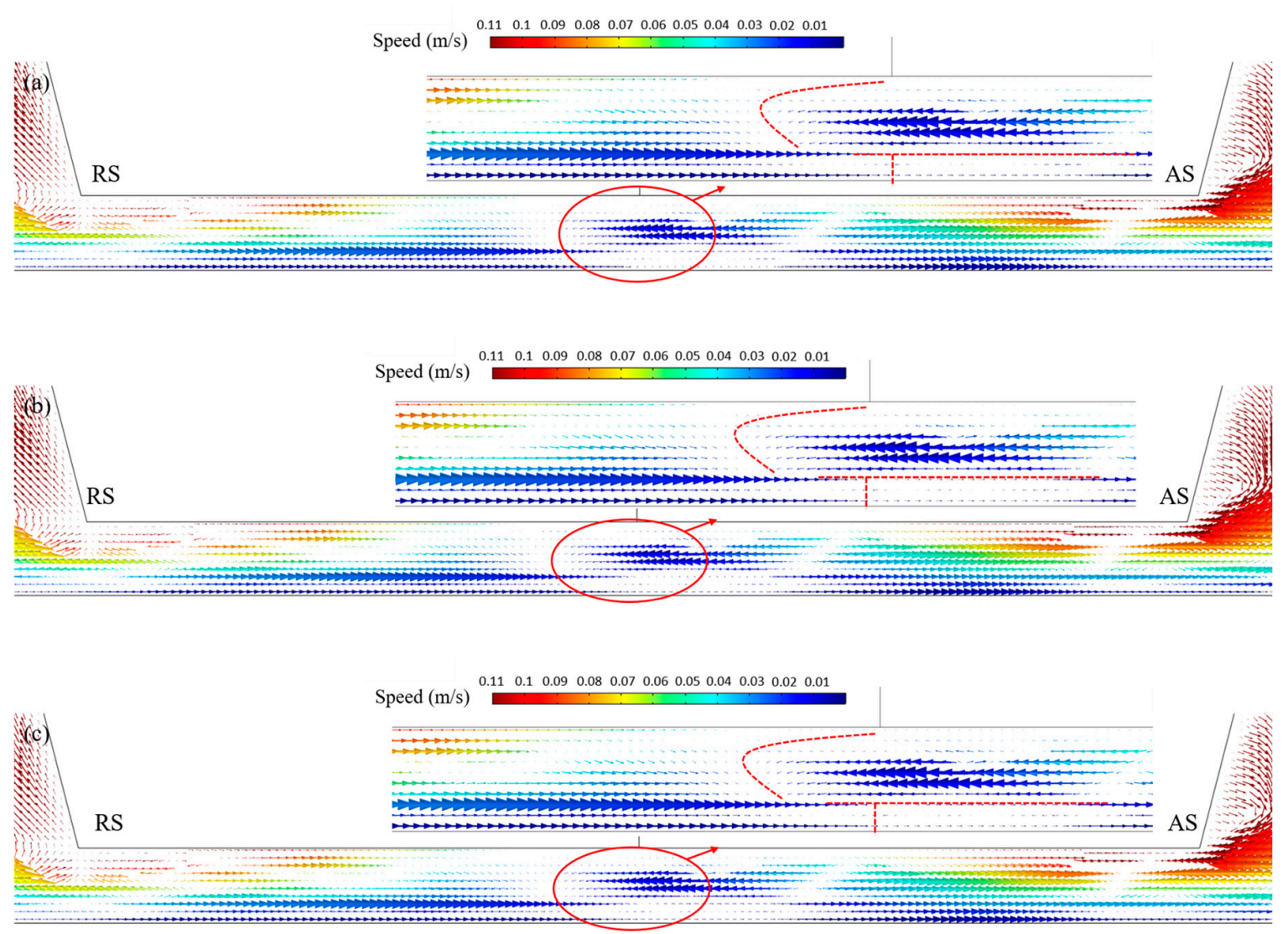

Figure 19. Cont. 

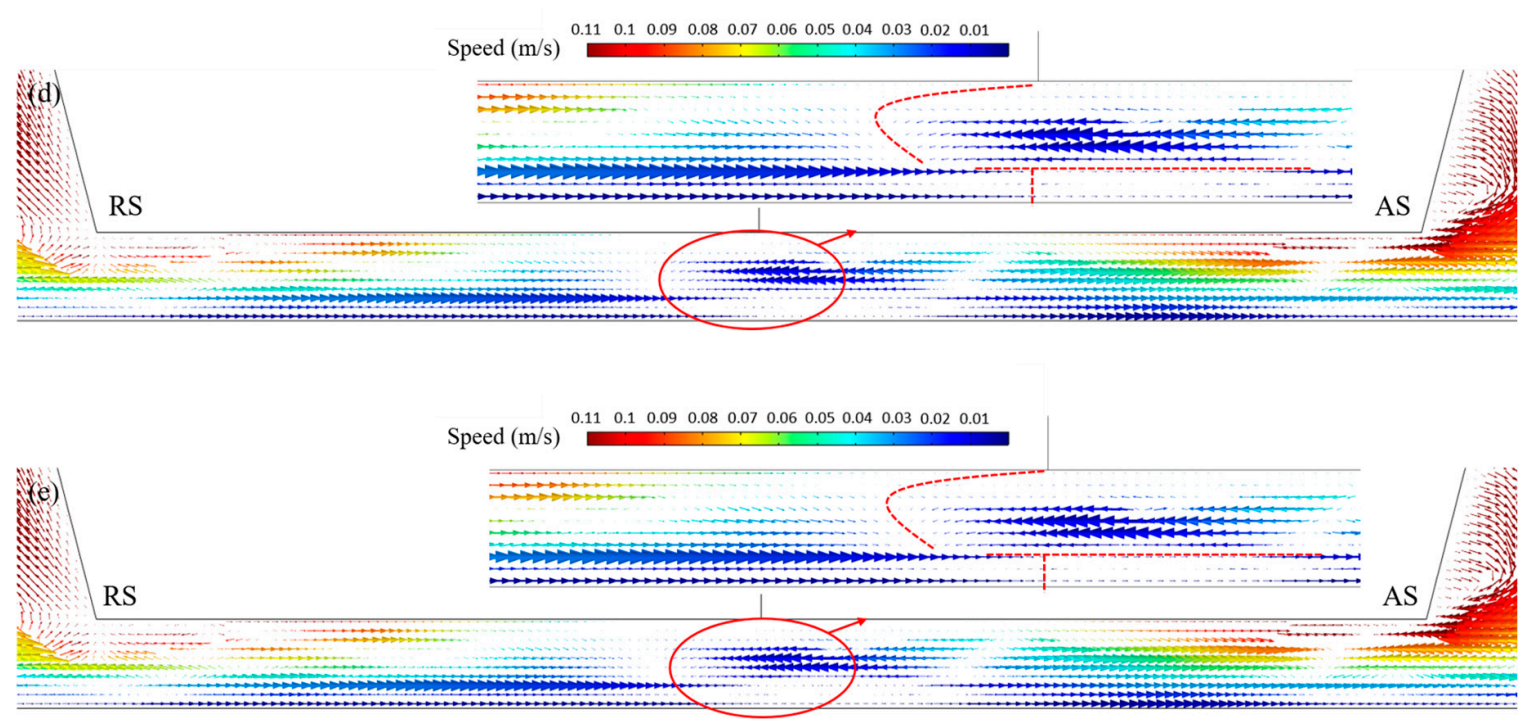

Figure 19. Flow behavior of plastic metal at different temperatures (a) No. 1; (b) No. 2; (c) No. 3; (d) No. 4 ; (e) No. 5.

The flow behavior at the bottom of the weld is due to the lack of shear stress on the plastic metal by agitation. The distribution of shear stress at the bottom of the weld is illustrated in Figure 20. When the temperature at the bottom of weld decreases gradually, the shear stress of the plastic metal at the bottom of weld seam increases gradually. In the position of the weld center, the shear stress is the smallest - that is, plastic metal at the bottom of the weld is the weakest. When the temperature at the bottom of the weld decreases, the viscosity of the plastic metal increases, and the critical driving force required for its flow increases. Therefore, when the temperature at the bottom of the weld decreases, although the shear effect of agitation on the plastic metal at the bottom is enhanced, the flow of the plastic metal is not improved.
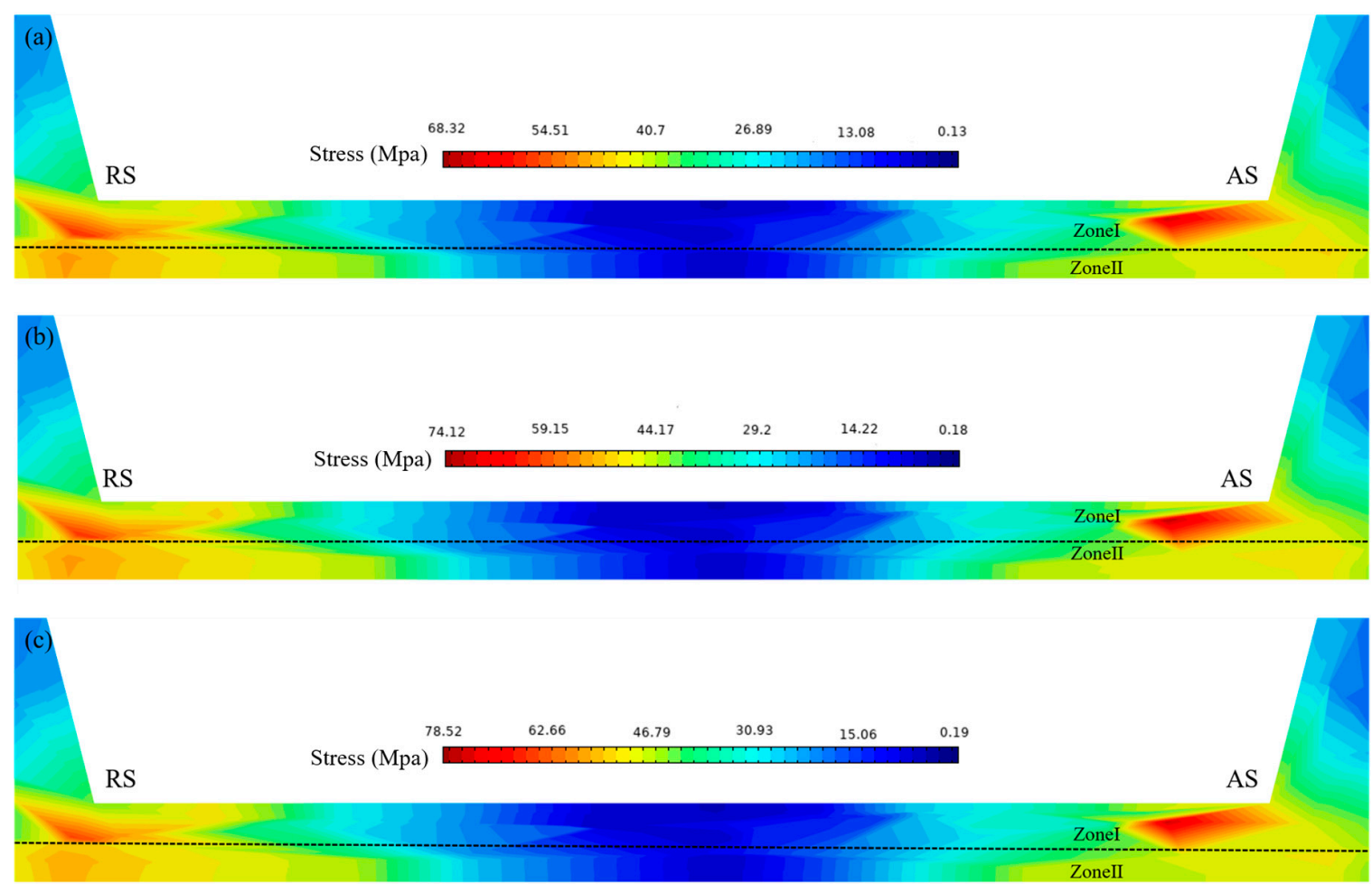

Figure 20. Cont. 

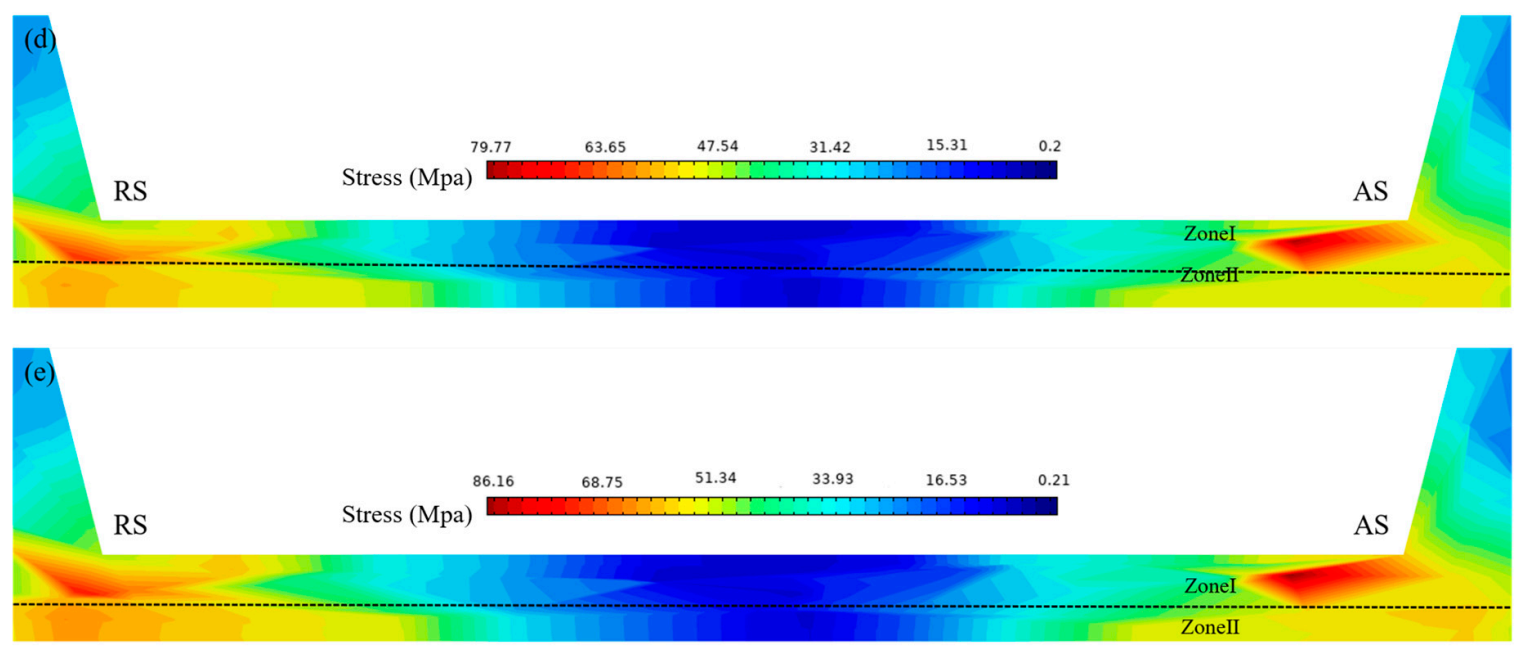

Figure 20. Distribution of shear stress at the root of the joint at different temperatures. (a) No. $1 ;$ (b) No. 2; (c) No. 3; (d) No. 4; (e) No. 5.

\section{Conclusions}

In this paper, material flow behavior at the root of the FSW weld is studied through an established 3D thermal-mechanical coupled FSW model. The results are as follows:

(1) The material at the root of the FSW welding seam can be divided into two different zones according to flow behavior. The material near the bottom surface of the pin is zone I, where material from AS and RS flow in opposite directions and mix on the RS side near the weld center. The material near the bottom surface of the workpiece is zone II, where the material flows in the same direction near the weld center.

(2) Owing to the low pressure and shear stress at the weld center, the fluidity of the material is low in the central area of zones I and II. The "S line" defect will appear at the RS side of zone I when the material is not fully mixed owing to low fluidity. Furthermore, the non-penetration defect will appear at the center of zone II when the material in zone II cannot flow through the weld center.

(3) With the increase of the pin length, the material flow behavior changes significantly on the margin of the pin of the RS side, and the shape of the "s line" defect also changes to the "right-tilting line" shape. If the pin length further increases, the tilting angle of the "right-tilting line" reduces, and the sizes of the "s line" defect and non-penetration decrease. The "s line" defect and non-penetration defect are finally eliminated when the pin length increases to a certain extend.

(4) In this paper, the optimal pin length is $5.95 \mathrm{~mm}$ under a $6 \mathrm{~mm}$ butt FSW welded joint of aluminum alloy, which is determined from two aspects. On the one hand, if the pin length is shorter than $5.95 \mathrm{~mm}$, the thickness of zone II is not negligible, which will result in the insufficient fluidity of the material near the bottom surface of workpiece so that non-penetration defect is prone to occur. On the other hand, if the pin length is longer than $5.95 \mathrm{~mm}$, the temperature at the root of the weld will increase to a relatively high level, which will coarsen the recrystallization tissue and degrade the mechanical properties of the FSW joint or even make an intense wear of stirring pin, reducing the stability of FSW process.

Author Contributions: J.L.: Supervision, writing, review and editing. J.W.: Formal analysis, methodology, data curation, writing, and original draft. H.L.: Conceptualization, data curation, writing, and reviewing. L.Y.: Software, validation. J.G.: Investigation, software, writing, and reviewing. H.G.: Investigation, writing, editing, and formal analysis. All authors have read and agreed to the published version of the manuscript.

Funding: Support Program of State Key Lab of Advanced Welding and Joining, Harbin Institute of Technology (AWJ-20-Z02), the State Key Laboratory of Solidification Processing in Northwestern Polytechnical University (SKLSP201903), and the Minjiang Scholar Support Program of Fujian, China (2016). 
Acknowledgments: The authors acknowledge the financial support from the State Key Lab of Advanced Welding and Joining, Harbin Institute of Technology (AWJ-20-Z02), the State Key Laboratory of Solidification Processing in Northwestern Polytechnical University (SKLSP201903), and the Minjiang Scholar Support Program of Fujian, China. The authors are also thankful to Qingzhong Liu, Associate Professor in the Department of Computer Science at Sam Houston State University, USA, for his help with some revision suggestions.

Conflicts of Interest: The authors declare that they have no known competing financial interests or personal relationships that could have appeared to influence the work reported in this paper.

\section{References}

1. Thomas, W.M.; Nicholas, E.D.; Needham, J.C. Friction Stir Butt Welding: Great. Britain Patent Application. No. 9125978.8, 8 December 1991.

2. Mishra, R.S.; Ma, Z.Y. Friction stir welding and processing. Mater. Sci. Eng. R-Rep. 2005, 50, 1-78. [CrossRef]

3. Luo, J.; Li, F.; Chen, W. Experimental researches on resistance heat aided friction stir welding of Mg alloy. Q. J. Jpn. Weld. Soc. 2013, 31, 65-68. [CrossRef]

4. Song, Z.; Nakata, K.; Wu, A.; Liao, J.; Zhou, L. Influence of probe offset distance on interfacial microstructure and mechanical properties of friction stir butt welded joint of Ti6Al4V and A6061 dissimilar alloys. Mater. Des. 2014, 57, 269-278. [CrossRef]

5. Salih, O.S.; Ou, H.; Sun, W.; Mccartney, D.G. A review of friction stir welding of aluminium matrix composites. Mater. Des. 2015, 86, 61-71. [CrossRef]

6. Jia, Y.; Lin, S.C.; Liu, J.Z.; Qin, Y.G.; Wang, K.H. The influence of pre- and post-heat treatment on mechanical properties and microstructures in friction stir welding of dissimilar age-hardenable aluminum alloys. Metals 2019, 9, 1162. [CrossRef]

7. $\quad$ Oliveira, J.P.; Duarte, J.F.; Inácio, P.; Schell, N.; Miranda, R.M.; Santos, T.G. Production of Al/NiTi composites by friction stir welding assisted by electrical current. Mater. Des. 2017, 113, 311-318. [CrossRef]

8. Wan, L.; Huang, Y.X. Microstructure and mechanical properties of Al/Steel friction stir lap weld. Metals 2017, 7, 542. [CrossRef]

9. Zhou, C.; Yang, X.; Luan, G. Effect of kissing bond on fatigue behavior of friction stir welds on Al 5083 alloy. J. Mater. Sci. 2006, 41, 2771-2777. [CrossRef]

10. Sato, Y.S.; Takauchi, H.; Park, S.H.C.; Kokawa, H. Characteristics of the kissing-bond in friction stir welded Al alloy 1050. Mater. Sci. Eng. A-Struct. Mater. Prop. Microstruct. Process. 2005, 405, 333-338. [CrossRef]

11. Khan, N.Z.; Siddiquee, A.N.; Khan, Z.A.; Shihab, S.K. Investigations on tunneling and kissing bond defects in FSW joints for dissimilar aluminum alloys. J. Alloys. Compd. 2015, 648, 360-367. [CrossRef]

12. Le Jolu, T.; Morgeneyer, T.F.; Denquin, A.; Sennour, M.; Laurent, A.; Besson, J.; Gourgues, L. Microstructural Characterization of Internal Welding Defects and Their Effect on the Tensile Behavior of FSW Joints of AA2198 Al-Cu-Li Alloy. Metall. Mater. Trans. A-Phys. Metall. Mater. Sci. 2014, 45A, 5531-5544. [CrossRef]

13. Le Jolu, T.; Morgeneyer, T.F.; Denquin, A.; Gourgues, L. Fatigue lifetime and tearing resistance of AA2198 Al-Cu-Li alloy friction stir welds: Effect of defects. Int. J. Fatigue 2015, 70, 463-472. [CrossRef]

14. Le Jolu, T.; Morgeneyer, T.F.; Gourgues, L. Effect of joint line remnant on fatigue lifetime of friction stir welded Al-Cu-Li alloy. Sci. Technol. Weld. Join. 2010, 15, 694-698. [CrossRef]

15. Zhou, C.Z.; Yang, X.Q.; Luan, G.H. Effect of root flaws on the fatigue property of friction stir welds in 2024-T3 aluminum alloys. Mater. Sci. Eng. A-Struct. Mater. Prop. Microstruct. Process. 2006, 418, 155-160. [CrossRef]

16. Kadlec, M.; Růžek, R.; Nováková, L. Mechanical behaviour of AA 7475 friction stir welds with the kissing bond defect. Int. J. Fatigue 2015, 74, 7-19. [CrossRef]

17. Sato, Y.S.; Yamashita, F.; Sugiura, Y.; Park, S.H.C.; Kokawa, H. FIB-assisted TEM study of an oxide array in the root of a friction stir welded aluminium alloy. Scr. Mater. 2004, 50, 365-369. [CrossRef]

18. Okamura, H.; Aota, K.; Sakamoto, M.; Ezumi, M.; Ikeuchi, K. Behavior of oxides during friction stir welding of aluminium alloy and their effect on its mechanical properties. Weld. Int. 2002, 16, 266-275. [CrossRef]

19. Chen, G.; Li, H.; Shi, Q. On the material bonding behaviors in friction stir welding. In Friction Stir Welding and Processing; X (The Minerals, Metals \& Materials Series); Springer: Cham, Switzerland, 2019; pp. 99-108. Available online: https://link.springer.com/chapter/10.1007/978-3-030-05752-7_10\#citeas (accessed on 12 February 2019).

20. Luo, J.; Li, S.X.; Chen, W.; Xiang, J.F. Wang Hong. Simulation of aluminum alloy flowing in friction stir welding with a multiphysics field model. Int. J. Adv. Manuf. Technol. 2015, 81, 349-360. [CrossRef] 
21. Al-Moussawi, M.; Smith, A.J. Defects in Friction Stir Welding of Steel. Metallogr. Microstruct. Anal. 2018, 7 , 194-202. [CrossRef]

22. Hou, X.; Yang, X.; Cui, L.; Zhou, G. Influences of joint geometry on defects and mechanical properties of friction stir welded AA6061-T4 T-joints. Mater. Des. 2014, 53, 112-123. [CrossRef]

23. Zhou, N.; Song, D.; Qi, W.; Li, X.; Zou, J.; Attallah, M.M. Influence of the kissing bond on the mechanical properties and fracture behavior of AA5083-H112 friction stir welds. Mater. Sci. Eng. A-Struct. Mater. Prop. Microstruct. Process. 2018, 719, 12-20. [CrossRef]

24. Santos, T.G.; Miranda, R.M.; Vilaça, P. Friction Stir Welding assisted by electrical Joule effect. J. Mater. Process. Technol. 2014, 214, 2127-2133. [CrossRef]

25. Luo, J.; Chen, W.; Fu, G. Hybrid-heat effects on electrical-current aided friction stir welding of steel, and Al and Mg alloys. J. Mater. Process. Technol. 2014, 214, 3002-3012. [CrossRef]

26. Luo, J.; Wang, X.J.; Wang, J.X. New technological methods and designs of stir head in resistance friction stir welding. Sci. Technol. Weld. Join. 2009, 14, 650-654. [CrossRef]

27. Fuse, K.; Badheka, V. Bobbin tool friction stir welding: A review. Sci. Technol. Weld. Join. 2019, 24, $277-304$. [CrossRef]

28. Wang, F.F.; Li, W.Y.; Shen, J.; Wen, Q.; Dos Santos, J.F. Improving weld formability by a novel dual-rotation bobbin tool friction stir welding. J. Mater. Sci. Technol. 2018, 34, 135-139. [CrossRef]

29. Liu, H.; Hu, Y.; Wang, H.; Du, S.; Sekulic, D.P. Stationary shoulder supporting and tilting pin penetrating friction stir welding. J. Mater. Process. Technol. 2018, 255, 596-604. [CrossRef]

30. Kumar, S. Ultrasonic assisted friction stir processing of 6063 aluminum alloy. Arch. Civ. Mech. Eng. 2016, 16, 473-484. [CrossRef]

31. Tarasov, S.Y.; Rubtsov, V.Y.; Kolubaev, E.A.; Ivanov, A.N.; Fortuna, S.V.; Eliseev, A.A. Ultrasonic-Assisted Friction Stir Welding on V95AT1 (7075) Aluminum Alloy. AIP Conf. Proc. 2015, 1683, 020231.

32. Salari, E.; Jahazi, M.; Khodabandeh, A.; Ghasemi-Nanesa, H. Influence of tool geometry and rotational speed on mechanical properties and defect formation in friction stir lap welded 5456 aluminum alloy sheets. Mater. Des. 2014, 58, 381-389. [CrossRef]

33. Do Vale, N.L.; Torres, E.A.; Santos, T.F.D.A.; Urtiga Filho, S.L.; Dos Santos, J.F. Effect of the energy input on the microstructure and mechanical behavior of AA2024-T351 joint produced by friction stir welding. J. Braz. Soc. Mech. Sci. Eng. 2018, 40, 467-481. [CrossRef]

34. Mandache, C.; Levesque, D.; Dubourg, L.; Gougeon, P. Non-destructive detection of lack of penetration defects in friction stir welds. Sci. Technol. Weld. Join. 2012, 17, 295-303. [CrossRef]

35. Riahi, M.; Nazari, H. Analysis of transient temperature and residual thermal stresses in friction stir welding of aluminum alloy 6061-T6 via numerical simulation. Int. J. Adv. Manuf. Technol. 2011, 55, 143-152. [CrossRef]

36. Ren, J.G.; Wang, L.; Xu, D.K.; Xie, L.Y.; Zhang, Z.C. Analysis and Modeling of Friction Stir Processing-Based Crack Repairing in 2024 Aluminum Alloy. Acta Metall. Sin. (Engl. Lett.) 2017, 30, 228-237. [CrossRef]

37. Zeng, X.H.; Xue, P.; Wang, D.; Ni, D.R.; Xiao, B.L.; Ma, Z.Y. Effect of Processing Parameters on Plastic Flow and Defect Formation in Friction-Stir-Welded Aluminum Alloy. Met. Mater. Trans. A 2018, 49, 2673-2683. [CrossRef]

38. Hernández, C.A.; Ferrer, V.H.; Mancilla, J.E.; Mart'ınez, C. Three-dimensional numerical modeling of the friction stir welding of dissimilar steels. Int. J. Adv. Manuf. Technol. 2017, 93, 1-15. [CrossRef]

(C) 2020 by the authors. Licensee MDPI, Basel, Switzerland. This article is an open access article distributed under the terms and conditions of the Creative Commons Attribution (CC BY) license (http://creativecommons.org/licenses/by/4.0/). 